\title{
Argon release mechanisms of biotite in vacuo and the role of short-circuit diffusion and recoil
}

\author{
Ching-Hua Lo ${ }^{\text {a, }}{ }^{\text {, James K.W. Lee }}{ }^{\mathrm{b}}$, Tullis C. Onstott ${ }^{\mathrm{c}}$ \\ a Department of Geology, National Taiwan University, 245 Choushan Road, Taipei 106, Taiwan \\ b Department of Geological Sciences and Geological Engineering, Queen's University, Kingston, Ontario, Canada K7L $3 N 6$ \\ ${ }^{\mathrm{c}}$ Department of Geosciences, Princeton University, Princeton, NJ 08544-1003, USA
}

Received 29 October 1998; accepted 23 July 1999

\begin{abstract}
Understanding argon release mechanisms in K-bearing minerals is essential in interpreting the ${ }^{40} \mathrm{Ar} /{ }^{39} \mathrm{Ar}$ data and their application to geological studies. The release mechanisms of argon in vacuo have been examined in a series of ${ }^{40} \mathrm{Ar} /{ }^{39} \mathrm{Ar}$ isothermal heating experiments on two biotite specimens with $\mathrm{Fe} /(\mathrm{Fe}+\mathrm{Mg})\left(\mathrm{Fe}^{\#}\right)=0.50$ and 0.87 respectively. The crystal structure of the biotite was also monitored during in vacuo heating by an in-situ high temperature X-ray diffractometer (HTXRD), and also examined by scanning electron microscopy (SEM). At temperatures greater than $600^{\circ} \mathrm{C}$, argon release is mainly controlled by the structural decomposition of the biotite crystal arising from oxidation and dehydroxylation, whereas at temperatures less than $600^{\circ} \mathrm{C}$, argon release appears to be controlled by a multipath-diffusion mechanism, with effective $D / a^{2}$ values about 2-4 orders of magnitude higher than those extrapolated from hydrothermal data. Both the argon diffusivity and Ar release patterns are strongly related to biotite composition, in which the Fe-rich biotite has a higher argon diffusivity and degasses at lower temperatures than the $\mathrm{Mg}$-rich biotite. Unless contaminated by other phases, biotites will tend to yield flat age spectra for temperature steps higher than $600^{\circ} \mathrm{C}$, regardless of the initial distribution of argon isotopes in the crystal structure, since the argon released at $T>600^{\circ} \mathrm{C}$ is strongly correlated with the decomposition process. At temperature steps lower than $600^{\circ} \mathrm{C}$, however, biotite age spectra can exhibit discordant dates since the gas release is controlled mainly by defect-enhanced (short-circuit) diffusion mechanisms. Consequently, models using such low- $T$ steps with the intent of extracting information on the spatial distribution of Ar will not lead to accurate interpretations of geologic histories, unless the potential effects of short-circuit diffusion are well-constrained. (C) 2000 Elsevier Science B.V. All rights reserved.
\end{abstract}

Keywords: Geochronology; Argon; Diffusion; Biotite

\section{Introduction}

One of the most important advantages of ${ }^{40} \mathrm{Ar} /{ }^{39} \mathrm{Ar}$ dating over conventional $\mathrm{K}-\mathrm{Ar}$ dating is the ability

\footnotetext{
* Corresponding author. Tel.: +886-2-23635880; fax: +886-23636095; E-mail: loch@ccms.ntu.edu.tw
}

to infer the spatial distribution of ${ }^{40} \mathrm{Ar} *$ within the analyzed mineral using the step-heating technique. This inference is based upon the application of solid-state (or volume) diffusion theory to describe argon transfer in minerals during natural thermal events and laboratory experiments (McDougall and Harrison, 1988, and references therein). 
In natural events, the variation of biotite ${ }^{40} \mathrm{Ar} /{ }^{39} \mathrm{Ar}$ total-gas or $\mathrm{K}-\mathrm{Ar}$ dates observed near thermal contact aureoles and in some regional metamorphic terranes is consistent with volume-diffusion theory (Hart, 1964; Westcott, 1966; Hanson and Gast, 1967; Harrison and McDougall, 1980; Onstott et al., 1989). A number of other studies (as reviewed by McDougall and Harrison, 1988) have also obtained disturbed biotite age spectra which were interpreted to reflect thermal resetting as predicted by volumediffusion theory. Moreover, the good correlation between the grain size, corresponding ${ }^{40} \mathrm{Ar} /{ }^{39} \mathrm{Ar}$ age, and cooling history for biotites suggests that $\mathrm{Ar}$ transfer mechanisms in biotite in natural settings are dominated by a volume-diffusion process (Wright et al., 1991). The diffusion-controlled distribution of argon in biotites has also been demonstrated recently by the ${ }^{40} \mathrm{Ar} /{ }^{39} \mathrm{Ar}$ laser microprobe (Pickles et al., 1997).

There are several other ${ }^{40} \mathrm{Ar} /{ }^{39} \mathrm{Ar}$ studies, however, in which the distribution of argon in biotite cannot be readily explained by volume diffusion, e.g., the laser microprobe studies of Phillips and Onstott (1988), Onstott et al. (1991), and Phillips (1991). Moreover, other studies have suggested that volume-diffusion theory may not be appropriate for interpreting the age spectra of biotite because the temperatures used in in vacuo ${ }^{40} \mathrm{Ar} /{ }^{39} \mathrm{Ar}$ step-heating experiments extend beyond the stability field of biotite (Gaber et al., 1988; Lo and Onstott, 1989). Using XRD (X-ray diffraction) and SEM (scanning electron microscopy) techniques, Gaber et al. (1988) discovered that biotite experiences a complicated phase change in the temperature range of $600-800^{\circ} \mathrm{C}$, resulting in the reduction of cell parameters, structural delamination and weight loss. In addition, the fraction of argon released from biotite at these temperatures in vacuo $\left(600-800^{\circ} \mathrm{C}\right)$ greatly exceeded that predicted from volume diffusion. Consequently, they concluded that the rate of argon release from biotite during ${ }^{40} \mathrm{Ar} /{ }^{39} \mathrm{Ar}$ step-heating experiments is controlled by processes other than the volume diffusion, and that homogenization of the ${ }^{40} \mathrm{Ar} /{ }^{39} \mathrm{Ar}$ distribution should occur during such experiments (Gaber et al., 1988).

Laboratory studies of Ar diffusion in biotite have yielded equivocal results. Giletti (1974), Norwood (1974), Harrison et al. (1985) and Grove and Harri- son (1996) reported that the amount of ${ }^{40} \mathrm{Ar}^{*}$ lost from hydrothermally-treated biotite held at temperatures and pressures within its stability field was similar to that expected from volume diffusion, although interestingly the shape of the corresponding age spectra from these biotites could not be explained by this same theory (Harrison et al., 1985; Hess et al., 1987). In another hydrothermal study, the argon distribution pattern in biotite as determined by laser microprobe also could not be explained by a simple volume-diffusion model (Onstott et al., 1991). These studies strongly suggest that the release mechanisms of argon from biotite during ${ }^{40} \mathrm{Ar} /{ }^{39} \mathrm{Ar}$ in vacuo heating are different from those occurring in either natural or hydrothermal environments, and that a more detailed understanding of the Ar release mechanisms from biotite in vacuo is required.

\section{Experimental procedures}

In order to elucidate the argon release mechanisms for biotite in vacuo, a series of ${ }^{40} \mathrm{Ar} /{ }^{39} \mathrm{Ar}$ isothermal heating experiments, incremental stepheating runs, in-situ high-temperature X-ray diffraction (HTXRD) heating experiments, and SEM studies were conducted on two pure biotite samples with distinct chemical compositions.

\subsection{Starting materials}

Two biotite samples were selected for this study: one (KM) is an Fe-rich biotite extracted from a Cretaceous granite (90-109 Ma) occurring on Chinmen island located off the coast of SE China; the other (CPC), is a relatively $\mathrm{Mg}$-rich biotite extracted from a Tertiary tonalite (50-60 Ma) in the Coast Plutonic Complex Sill in SE Alaska. Previous ${ }^{40} \mathrm{Ar} /{ }^{39} \mathrm{Ar}$ studies showed that both plutonic bodies have experienced a simple and rapid cooling history without any notable reheating events (Wood et al., 1991; Lo et al., 1993). From these studies, both biotite separates yielded flat age spectra over more than $97 \%$ of ${ }^{39} \mathrm{Ar}_{\mathrm{K}}$ released with plateau dates of $97.2 \pm 0.9 \mathrm{Ma}$ for KM biotite and $56.4 \pm 0.4 \mathrm{Ma}$ for CPC biotite (Fig. 1). In thin section, KM biotite is greenish-brown to dark brown and coexists with $\mathrm{K}$-feldspar, plagioclase, quartz and some accessory 


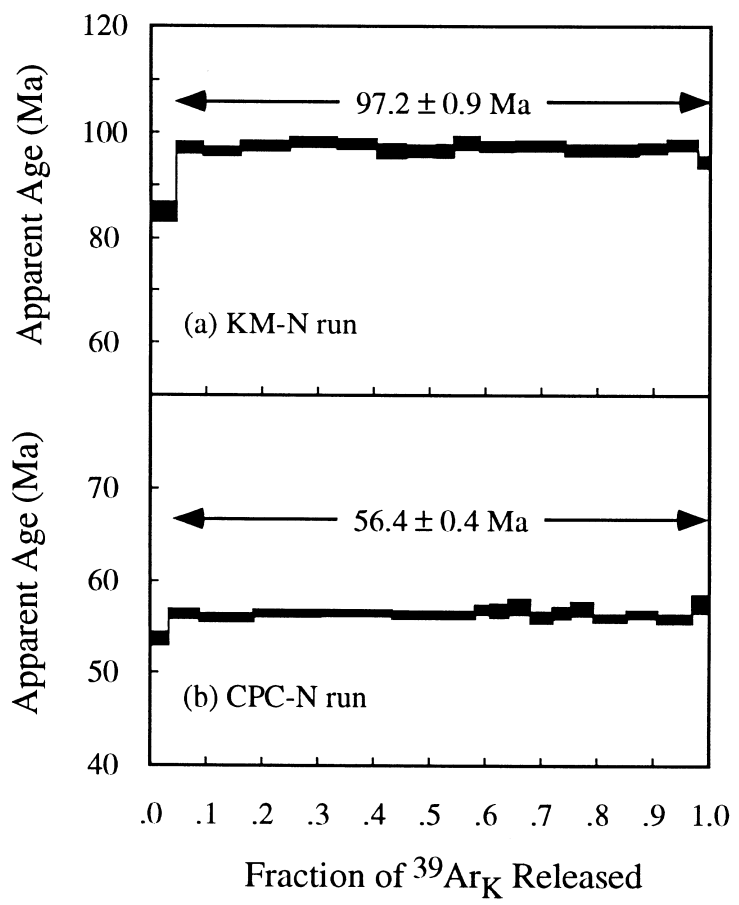

Fig. 1. ${ }^{40} \mathrm{Ar} /{ }^{39} \mathrm{Ar}$ age spectra for $\mathrm{KM}$ and $\mathrm{CPC}$ biotite in the normal step-heating runs. Vertical length of the bars indicates two standard deviations for apparent age, and horizontal length shows the relative fraction of ${ }^{39} \mathrm{Ar}$ loss.

oxides; CPC biotite is greenish-brown to pale brown, associated with plagioclase, quartz, hornblende, titanite, epidote and oxides. Alteration phases are not evident in these biotites. Electron microprobe analyses show that the chemical composition of both samples is generally homogeneous over the mineral grains, and no significant chemical variation was detected on the thin-section scale. The major difference between the two biotites is that $\mathrm{KM}$ biotite exhibits higher $\mathrm{Fe} /(\mathrm{Fe}+\mathrm{Mg})\left(\mathrm{Fe}^{\#}=0.87\right)$ and volatile contents $(\sim 4.68 \%)$ than $\mathrm{CPC}$ biotite $\left(\mathrm{Fe}^{\#}=\right.$ 0.50 and $3.82 \%$, respectively) (Table 1). Recasting the mineral formulae on the basis of 11 oxygens (assuming total $\mathrm{Fe}$ as $\mathrm{Fe}^{+2}$ ), both biotites show a deficiency of cations in both the octahedral and interlayer sites; comparison of the cation occupancy between the biotites indicates that KM biotite has a lower number of octahedral vacancies and higher number of interlayer vacancies than CPC biotite (Table 1).
Samples were prepared by crushing a whole-rock sample in a stainless steel mortar. Material was repeatedly sieved in order to obtain as uniform a size of mineral grains as possible. A size fraction of 80-120 mesh was used for the isothermal experiments. Biotite separates were obtained using standard heavy liquid and magnetic separation techniques, and hand picking was performed to achieve maximum purity. Most of the biotite flakes have elliptical or rectangular outlines, with a mean short radius of $75( \pm 22) \mu \mathrm{m}$ and a mean long radius of $118( \pm 34) \mu \mathrm{m}$ for KM biotite, and $84( \pm 19)$ and $133( \pm 38) \mu \mathrm{m}$, respectively, for CPC biotite. The samples were then split into several aliquots for ${ }^{40} \mathrm{Ar} /{ }^{39} \mathrm{Ar}, \mathrm{X}$-ray diffraction and SEM experiments at various temperatures.

Table 1

Chemical composition of the studied biotites

\begin{tabular}{|c|c|c|}
\hline & KM biotite & CRC biotite \\
\hline $\mathrm{SiO}_{2}$ & 33.76 & 36.46 \\
\hline $\mathrm{TiO}_{2}$ & 1.63 & 3.06 \\
\hline $\mathrm{Al}_{2} \mathrm{O}_{3}$ & 16.24 & 15.57 \\
\hline $\mathrm{FeO}$ & 31.13 & 19.79 \\
\hline $\mathrm{MgO}$ & 2.60 & 11.17 \\
\hline $\mathrm{MnO}$ & 1.20 & 0.35 \\
\hline $\mathrm{CaO}$ & 0.06 & 0.27 \\
\hline $\mathrm{Na}_{2} \mathrm{O}$ & 0.08 & 0.10 \\
\hline $\mathrm{K}_{2} \mathrm{O}$ & 8.54 & 9.35 \\
\hline $\mathrm{Cl}$ & 0.07 & 0.06 \\
\hline Anhydrous total & 95.31 & 96.18 \\
\hline $\mathrm{Fe} /(\mathrm{Fe}+\mathrm{Mg})$ & 0.871 & 0.498 \\
\hline $\mathrm{Ca} / \mathrm{K}$ & 0.006 & 0.024 \\
\hline $\mathrm{Cl} / \mathrm{K}$ & 0.011 & 0.009 \\
\hline \multicolumn{3}{|l|}{$11(O)$} \\
\hline $\mathrm{Si}$ & 2.747 & 2.768 \\
\hline $\mathrm{Ti}$ & 0.100 & 0.175 \\
\hline $\mathrm{Al}^{\mathrm{IV}}$ & 1.153 & 1.057 \\
\hline$\Sigma$ & 4.000 & 4.000 \\
\hline $\mathrm{Al}^{\mathrm{VI}}$ & 0.405 & 0.236 \\
\hline $\mathrm{Fe}$ & 2.118 & 1.256 \\
\hline $\mathrm{Mg}$ & 0.315 & 1.264 \\
\hline $\mathrm{Mn}$ & 0.083 & 0.023 \\
\hline$\Sigma$ & 2.926 & 2.902 \\
\hline $\mathrm{Ca}$ & 0.005 & 0.022 \\
\hline $\mathrm{Na}$ & 0.013 & 0.015 \\
\hline K & 0.886 & 0.906 \\
\hline$\Sigma$ & 0.904 & 0.943 \\
\hline $\mathrm{Cl}$ & 0.010 & 0.008 \\
\hline
\end{tabular}




\section{2. ${ }^{40} \mathrm{Ar} /{ }^{39} \mathrm{Ar}$ experiments}

The samples were wrapped in aluminum foil packets, stacked in an aluminum canister with the irradiation standard P-207 muscovite $(82.6 \pm 1.0 \mathrm{Ma}$, Dalrymple et al., 1981), and irradiated in the 5C position of the McMaster University research reactor. One of the aliquots of KM biotite (KM-N) used for normal step-heating was irradiated with the irradiation standard Mmhb-1 (520.4 \pm 1.4 Ma, Sampson and Alexander, 1987) in another canister. KM-N was irradiated for $20 \mathrm{~h}$, whereas the remainder of the samples were irradiated for $10 \mathrm{~h}$. The neutron flux gradient across the top and bottom of the irradiation canisters was less than $0.9 \%$, as indicated by the variation of $\mathbf{J}$ values from the flux monitors. After irradiation, the samples were weighed, loaded into fused-silica boats, and heated with a Lindberg resistance furnace. The released gas was purified with a $\mathrm{Ti}$ sponge and $\mathrm{Zr}-\mathrm{Al}$ getters, and analyzed with a Varian-MAT GD150 mass spectrometer. All isotope analyses were corrected for system blanks, the radioactive decay of the ${ }^{37} \mathrm{Ar}$ and ${ }^{39} \mathrm{Ar}$ isotopes, and minor interference reactions from $\mathrm{Ca}, \mathrm{Cl}$ and $\mathrm{K}$. The full ${ }^{40} \mathrm{Ar} /{ }^{39} \mathrm{Ar}$ analytical procedure and data reduction methods are outlined in Onstott and Peacock (1987). For the normal step-heating runs, the samples were stepwise-degassed according to a fixed schedule of $30 \mathrm{~min} / \mathrm{step}$ from $550^{\circ} \mathrm{C}$ to $1150^{\circ} \mathrm{C}$. In addition, a series of in vacuo heating experiments were conducted which combined isothermal and stepwise-heating methods. In these runs, the samples were heated to the desired isothermal temperature and analyzed over period of about $44 \mathrm{~h}$; after completion of the isothermal portion of the run, the samples were then degassed following the schedule used in the normal step-heating run until sample fusion (usually around $1150-1190^{\circ} \mathrm{C}$ ). The hightemperature isothermal runs $\left(800^{\circ} \mathrm{C}\right)$ included two low-temperature steps $\left(650^{\circ} \mathrm{C}\right.$ and $\left.750^{\circ} \mathrm{C}\right)$ lasting a total of an hour to permit gradual thermal equilibration before the furnace temperature was raised to $800^{\circ} \mathrm{C}$. During the isothermal heating, the gas was collected in intervals ranging from $5 \mathrm{~min}$ to $10 \mathrm{~h}$ depending on the amount of gas release, and the heating time was recorded as the total time elapsed from the time that the temperature reading on thermocouple reached the desired isothermal tempera- ture. The detailed time-temperature schedules and analytical data are given in Appendix A. The name of each ${ }^{40} \mathrm{Ar} /{ }^{39} \mathrm{Ar}$ run was chosen according to the temperature of the isothermal steps, e.g., KM-400 indicates a $400^{\circ} \mathrm{C}$ isothermal run for $\mathrm{KM}$ biotite. After complete degassing at $\sim 1150^{\circ} \mathrm{C}$, the samples were unloaded from the extraction line and reweighed to obtain the total weight loss.

\subsection{High-temperature X-ray diffraction and SEM}

In-situ high temperature X-ray diffraction (HTXRD) data were obtained from an automated Scintag PAD V diffractometer using $\mathrm{CuK}_{\alpha}$ radiation and a scintillation detector, equipped with an in vacuo heating stage (a modified Anton Paar unit). Vacuum was held at about $10^{-3}$ Torr during the runs. Temperature was maintained using a PAAR HTK heat controller and measured using a Pt/ $13 \% \mathrm{Rh}-\mathrm{Pt}$ thermocouple, with an uncertainty of $\pm 10^{\circ} \mathrm{C}$. The position of heating stage was previously calibrated using the thermal expansion of $\mathrm{Pt}$, and a $\mathrm{Pt}$ sample holder served as an internal standard (Brown and Navrotsky, 1989). A crushed powder sample was first heated to $90^{\circ} \mathrm{C}$ to remove unbonded $\mathrm{H}_{2} \mathrm{O}$ and scanned continuously from $5^{\circ}$ to $70^{\circ} 2 \theta$. Subsequently, the samples were incrementally heated from $400^{\circ} \mathrm{C}$ to $1000^{\circ} \mathrm{C}$, in steps of $100^{\circ} \mathrm{C}$ for $\mathrm{KM}$ biotite and $50^{\circ} \mathrm{C}$ for $\mathrm{CPC}$ biotite. The duration for each step was $2 \mathrm{~h}$ for KM biotite and $70 \mathrm{~min}$ for CPC biotite. XRD peaks were step-scanned in $0.01^{\circ} 2 \theta$ increments at a rate of $0.5^{\circ} / \mathrm{min}$ and multi-scan mode was used to reduce the duration for each temperature step, except for the $1000^{\circ} \mathrm{C}$ run which was continuously scanned from $5^{\circ}$ to $70^{\circ}$. An additional isothermal HTXRD run at $700^{\circ} \mathrm{C}$ for $12 \mathrm{~h}$ was performed on KM biotite to examine any kinetic effects on the biotite phase change. Unit cell parameters and estimated errors were obtained by the refinement of 10 reflections [including (001), (002), (003), (004), (113), (005), $(1,3, \overline{5}),(204),(060),(\overline{3} 31)]$ over the range $5^{\circ}<2 \theta<70^{\circ}$ using the least squares procedure of Appleman and Evans (1973). SEM analyses were performed on CPC biotite grains after being heated at high temperatures under vacuum conditions, using a JEOL scanning electron microscope at Department of Biology, Princeton University. 


\section{Volume diffusion equations and computational method of diffusion parameters}

Argon diffusion in biotite has been best described as volume diffusion via cylindrical geometry (Giletti, 1974; Grove and Harrison, 1996). The fraction of gas lost from an infinite cylinder is given as (Crank, 1975):

$F=1-4 \sum_{n=1}^{\infty} \frac{1}{\alpha_{n}^{2}} \exp \left(-\frac{\alpha_{n}^{2} D t}{a^{2}}\right)$

where $a$ is the diffusion radius, $\alpha_{n}$ are the roots of $J_{0}\left(a \alpha_{n}\right)=0$ (where $J_{0}(x)$ is the Bessel function of the first kind of order zero), $D$ is the diffusion coefficient, and $t$ is the heating time. The change of $D$ with temperature $(T)$ is described by the Arrhenius relation $D=D_{0} \exp (-E / R T)$, where $D_{0}$ is the pre-exponential coefficient, $E$ is the activation energy, and $R$ is the gas constant. Since Eq. (1) does not converge rapidly for small $F$, two useful approximations have been utilized (Jost, 1960; Crank, 1975):

$\begin{aligned}(1) \text { for } 0<F<0.6: F= & \frac{4}{\pi^{1 / 2}}\left[\frac{D t}{a^{2}}\right]^{1 / 2}-\frac{D t}{a^{2}} \\ & -\frac{3}{\pi^{2}}\left(\frac{\pi^{2} D t}{a^{2}}\right)^{3 / 2}\end{aligned}$

(2) for $0.6<F<1$ : $F=1-\frac{4}{\alpha_{1}^{2}} \exp \left[-\frac{\alpha_{1}^{2} D t}{a^{2}}\right]$

where $\alpha_{1}$ is the first root of the Bessel function $J_{0}\left(a \alpha_{n}\right)=0$.

From Eqs. (2) and (3), an integrated $D / a^{2}$ value can be computed for the argon release from biotite, given the total fraction lost $(F)$ and the total heating time $(t)$ for each isothermal run. However, since the present experiments were designed to see if any changes in the argon release mechanism occurred during the isothermal runs, $D / a^{2}$ values for each step were calculated by considering the diffusivity of argon during the interval of time between each step by using the following equations:

(1) for $0<F<0.6:\left(D / a^{2}\right)$

$$
\begin{gathered}
=\frac{8}{\pi t}\left[\sqrt{1-\frac{\pi}{4} F_{i}}-\sqrt{1-\frac{\pi}{4} F_{i+1}}\right. \\
\left.+\frac{\pi}{8}\left(F_{i}-F_{i+1}\right)\right] \text { for } i=0, n-1
\end{gathered}
$$

(2) for $0.6<F<1:\left(D / a^{2}\right)_{i+1}$

$$
=\frac{1}{\alpha_{1}^{2} t} \ln \left[\frac{\left(1-F_{i}\right)}{\left(1-F_{i+1}\right)}\right]
$$

where $n$ is the total number of steps in the isothermal run; $F_{0}=0$, and $F_{i}$ and $F_{i+1}$ are the cumulative fractions lost in the $i$ th and $(i+1)$ th isothermal steps; and $t=t_{i+1}-t_{i}$. Eq. (4) is derived from Eq. (2) using the first two terms and Eq. (5) is derived from Eq. (3). A detailed examination and discussion of the errors caused by these approximation equations in computing $D / a^{2}$ are given in Appendix B.

\section{HTXRD and SEM results}

The HTXRD-derived cell parameters of both biotite samples heated in vacuo are plotted against temperature (Fig. 2). All cell parameters lengthen from $90^{\circ} \mathrm{C}$ to $500^{\circ} \mathrm{C}$, suddenly decrease at around $600^{\circ} \mathrm{C}$, reaching minimum values in the temperature range of $600-850^{\circ} \mathrm{C}$, and then gradually increase again to $1000^{\circ} \mathrm{C}$. All of the reflection peaks persist to $1000^{\circ} \mathrm{C}$ with a slight decrease of reflection intensities after $950^{\circ} \mathrm{C}$. In a separate isothermal HTXRD run of $\mathrm{KM}$ biotite at $700^{\circ} \mathrm{C}$ (Fig. 3), the unit cell parameter, $b$, decreased with time during the first $5 \mathrm{~h}$ and then remained relatively constant during the latter stages of isothermal heating; the $a$ and $c$ cell parameters also decreased slightly, although the magnitude of the changes were much smaller than $b$. This is consistent with the findings of Gaber et al. (1988), who also noted a decrease in cell parameter dimensions over the temperature range of $600-800^{\circ} \mathrm{C}$, accompanied by a weight loss of $0.72-0.83 \%$.

KM biotite was also observed to lose about 5.43$5.54 \%$ in weight after being heated to $1200^{\circ} \mathrm{C}$, whereas CPC biotite lost $3.19-3.65 \%$. These weight 

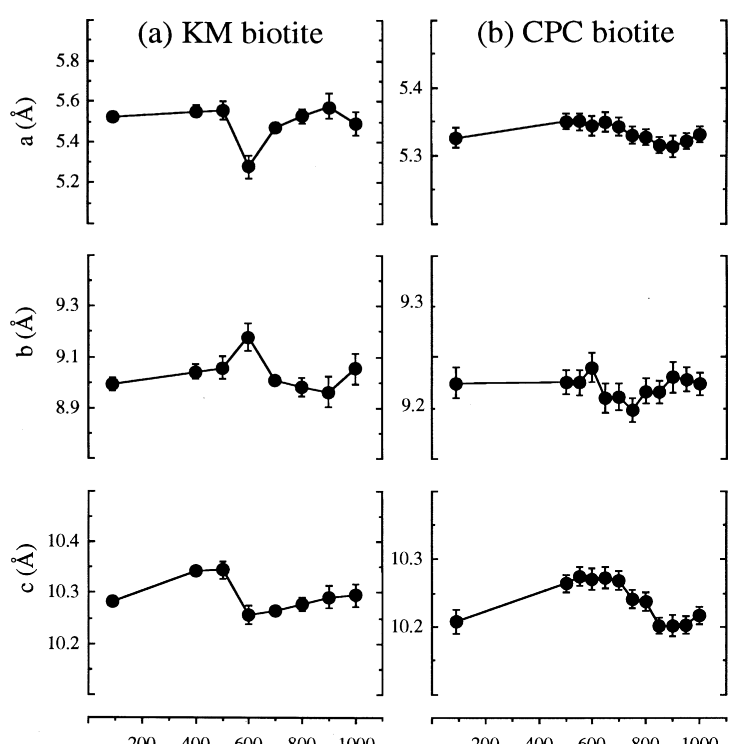

Temperature $\left({ }^{\circ} \mathrm{C}\right)$

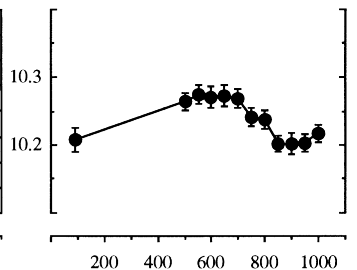

Temperature $\left({ }^{\circ} \mathrm{C}\right)$

Fig. 2. Change in the cell parameters of (a) KM biotite and (b) CPC biotite with temperature.

losses are very close to the volatile contents of samples, as inferred from the total anhydrous content obtained by microprobe analyses (Table 1).

SEM analyses show that CPC biotite grains did not change their structure below $640^{\circ} \mathrm{C}$, although they started to decompose along the surfaces of the cleavage planes at this temperature (Fig. 4). At temperatures above $700^{\circ} \mathrm{C}$, the biotite grains show sub-

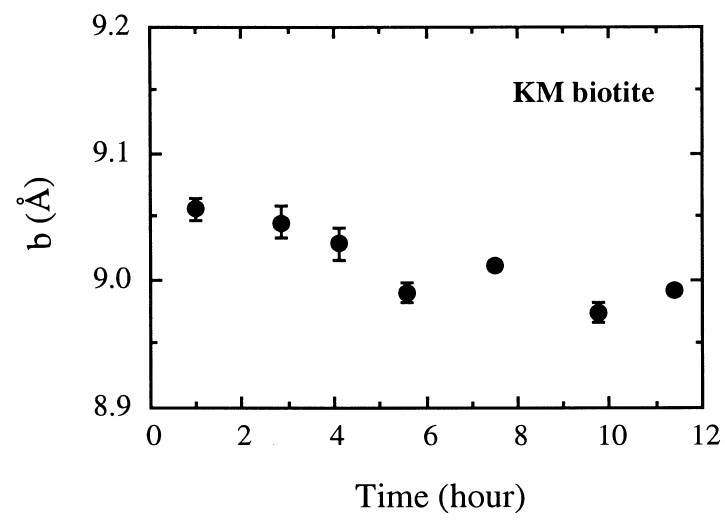

Fig. 3. Change in $b$ cell parameter of KM biotite with time for a $700^{\circ} \mathrm{C}$ HTXRD isothermal run.
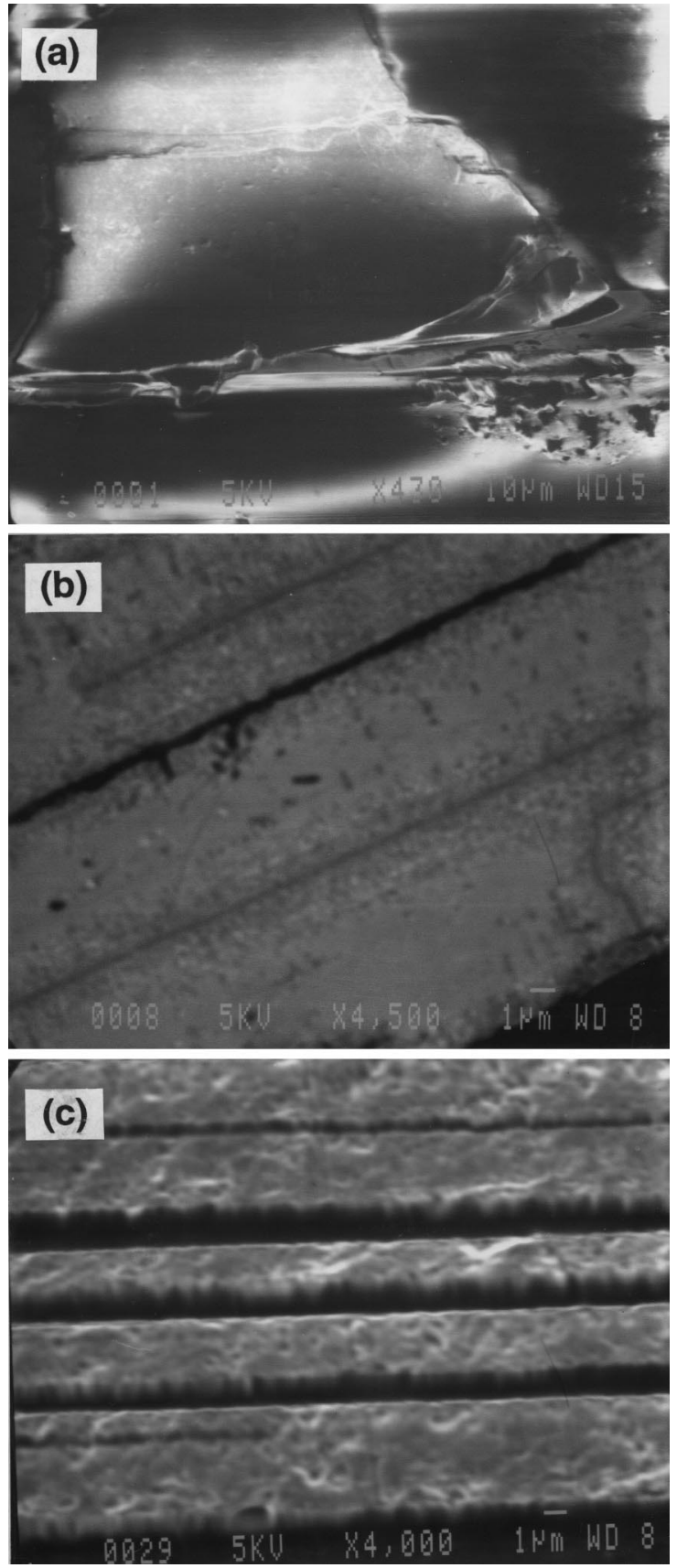

Fig. 4. SEM images of a flake of CPC biotite (a) before heating; (b) after heating at $640^{\circ} \mathrm{C}$ for $30 \mathrm{~min}$ in vacuo, some decomposition has taken place along the cleavage planes and on the grain surface; (c) after heating at $700^{\circ} \mathrm{C}$ for $30 \mathrm{~min}$, partings with spacing of few $\mu \mathrm{m}$ are well-developed. 
stantial morphological changes, in which partings with spaces of a few microns gradually developed along the original cleavage planes as a result of reaction-induced delamination (Fig. 4c).

\section{5. ${ }^{40} \mathrm{Ar}-{ }^{39} \mathrm{Ar}$ results}

\subsection{Age spectra}

The ${ }^{40} \mathrm{Ar} /{ }^{39} \mathrm{Ar}$ analytical data are presented in Appendix A and plotted as age spectra in Fig. 5. All of the age spectra exhibit plateaus over more than $97 \%$ of the ${ }^{39} \mathrm{Ar}_{\mathrm{K}}$ released and the plateau dates are indistinguishable among all of the isothermal runs for each sample. In the first few steps of the lowtemperature isothermal runs $\left(400^{\circ} \mathrm{C}\right.$ and $\left.500^{\circ} \mathrm{C}\right)$, anomalous low dates, comprising the first $\sim 1 \%$ of ${ }^{39} \mathrm{Ar}_{\mathrm{K}}$ release for $\mathrm{CPC}$ biotite and $\sim 3 \%$ for $\mathrm{KM}$ biotite, gradually climb to the plateau dates. This staircase feature is also evident in the first two steps of the KM-600 isothermal run, but does not occur in the $800^{\circ} \mathrm{C}$ isothermal runs (Fig. 5). The plateau dates obtained in this study are in agreement with those originally reported by Wood et al. (1991) and Lo et al. (1993).

The estimated $\mathrm{K}_{2} \mathrm{O}, \mathrm{CaO}$ and $\mathrm{Cl}$ contents, as derived from the concentrations of ${ }^{39} \mathrm{Ar}_{\mathrm{K}},{ }^{37} \mathrm{Ar}_{\mathrm{Ca}}$ and ${ }^{38} \mathrm{Ar}_{\mathrm{Cl}}$ for each sample are in the ranges of 8.00 $8.84 \%, 0.09-0.16 \%$ and $\sim 0.6 \%$ for KM biotite, and $10.01-10.24 \%, 0.06-0.12 \%$ and $0.11-0.12 \%$ for CPC biotite. These values are generally in agreement with those obtained by microprobe analyses (Table 1), and the $\mathrm{Ca} / \mathrm{K}$ spectra yield flat profiles (Fig. 5), indicating that the above age discordances in the initial stages of the low-temperature isothermal runs are not due to the outgassing of impurities in the samples.

\subsection{Argon loss during isothermal heating}

The isothermal ${ }^{40} \mathrm{Ar} /{ }^{39} \mathrm{Ar}$ heating data are plotted as $F$ vs. (time) $)^{1 / 2}$ in Fig. 6 (all runs) and Fig. 7 (low-temperature runs). Volume-diffusion argon loss curves for various $D / a^{2}$ values using a cylindrical geometry (Eq. (1)) are also shown for comparison.

The argon release curves during the low-temperature isothermal runs $\left(400^{\circ} \mathrm{C}\right.$ and $\left.500^{\circ} \mathrm{C}\right)$ are very close to those predicted by volume diffusion for both biotite samples. The release curves of the high-temperature isothermal-heating runs $\left(600^{\circ} \mathrm{C}\right.$ and $\left.800^{\circ} \mathrm{C}\right)$, however, are significantly different from those predicted by volume diffusion (Fig. 6). The rate of argon release at these temperatures $\left(>600^{\circ} \mathrm{C}\right)$ is very similar to that observed by Gaber et al. (1988) for the Std. 8 biotite, where argon loss was very rapid in the early stages of heating and gradually diminished with time. From Fig. 6, it is evident that the rate of argon loss at temperatures greater than $600^{\circ} \mathrm{C}$ from $\mathrm{KM}$ biotite and $\mathrm{CPC}$ biotite is not consistent with a volume-diffusion mechanism.

If argon release is controlled by a single diffusion mechanism, then the calculated $D / a^{2}$ values should be constant over the entire isothermal portion of the experiment. Consequently, calculated $D / a^{2}$ values are plotted against (time) $)^{1 / 2}$ in Fig. 7 for the isothermal runs. From Fig. 7, the variation among the $D / a^{2}$ values in the low-temperature isothermal runs is within about factor of five, which is much less than that in the high-temperature isothermal runs. With the exception of the CPC-400 run, the $D / a^{2}$ increases from minimum values to a maximum in 30-60 min, and then flattens out over the remainder of the run; the CPC-400 run yields constant $D / a^{2}$ values after about an hour of isothermal heating. The variations in $D / a^{2}$ in these low-temperature isothermal runs cannot be readily explained by the effects of a range of diffusion radii and/or the use of approximation equations (Eqs. (4) and (5)) in calculating $D / a^{2}$, since the total fraction lost for each sample over the entire period of isothermal heating is much less than 0.4 and the variation of $D / a^{2}$ is much greater than that which can be attributed to either the effects of a distribution of diffusion radii or the use of the approximation equations (as discussed in Appendix B).

Upon close examination of the argon release curves for the low-temperature isothermal runs (Fig. $7 \mathrm{a}-\mathrm{d})$, the curves can be subdivided into three segments. The first segment reflects a period of relatively fast change in the argon release rate during the initial stages of heating $\left(0-30 \mathrm{~min}\right.$ at $500^{\circ} \mathrm{C}$ and 0-60 min at $400^{\circ} \mathrm{C}$ ). The remaining two segments are approximated by linear trends with different $D / a^{2}$ values. The first linear array has a larger $D / a^{2}$ and extends from 1 to $10 \mathrm{~h}$ for KM-400, 

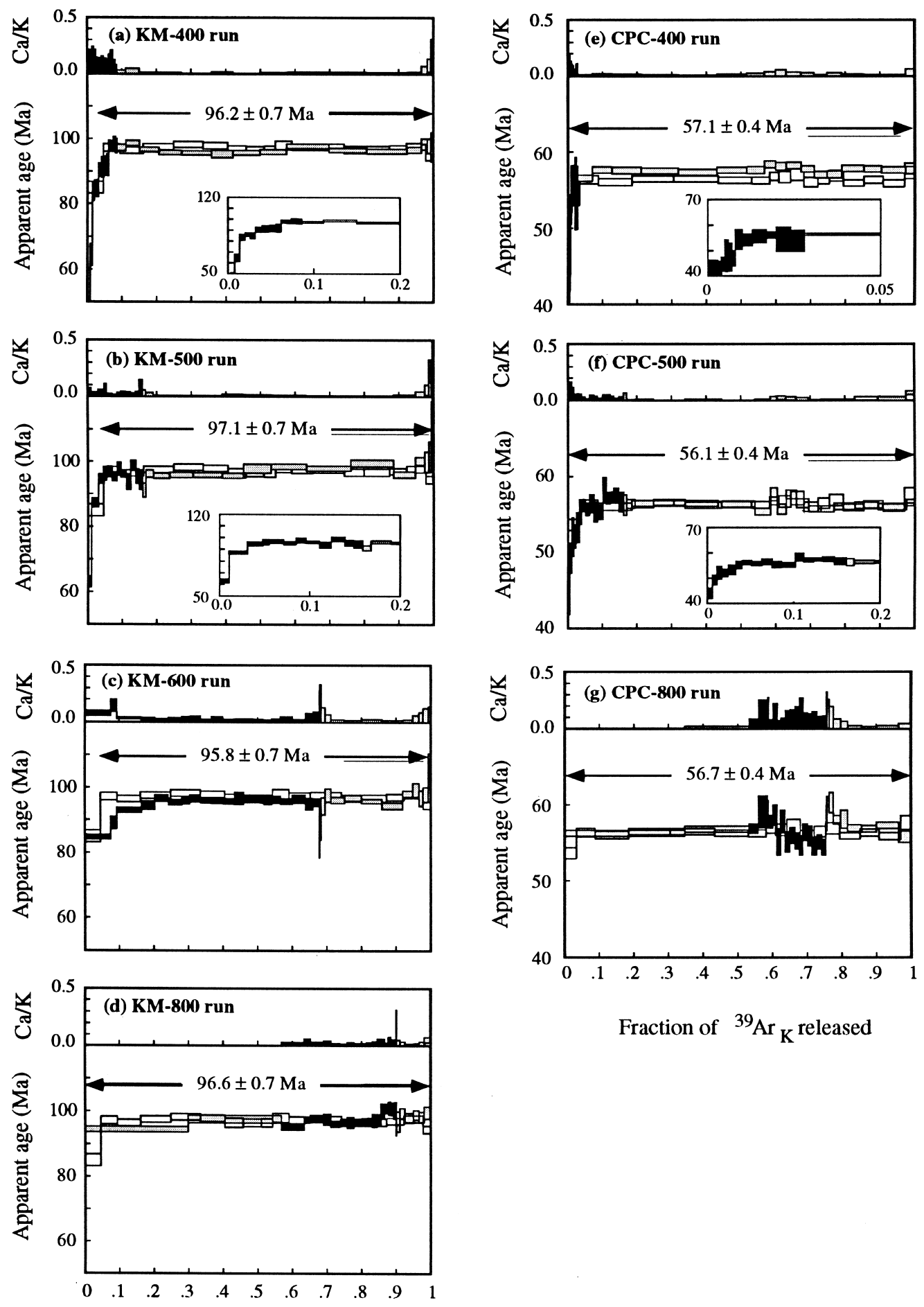

Fraction of ${ }^{39} \mathrm{Ar}_{\mathrm{K}}$ released

Fraction of ${ }^{39} \mathrm{Ar}_{\mathrm{K}}$ released 

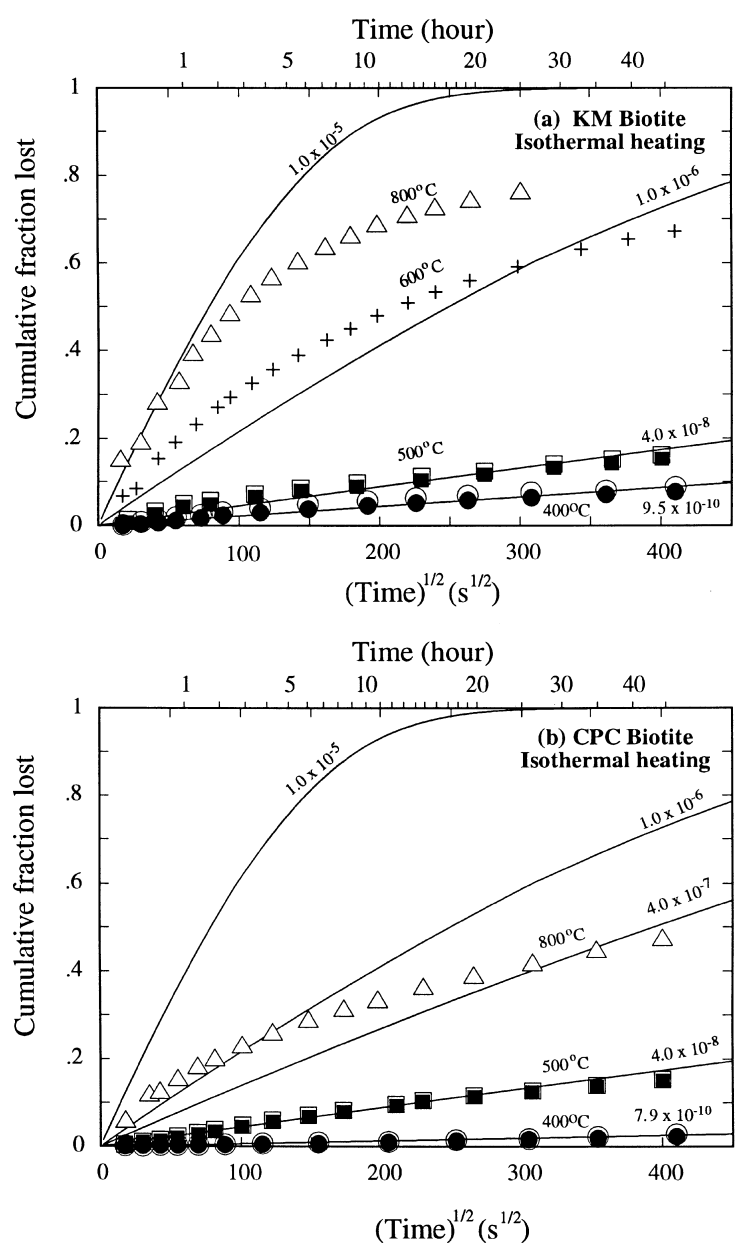

Fig. 6. The argon release from (a) KM biotite and (b) CPC biotite during isothermal in vacuo heating at $400^{\circ} \mathrm{C}$ (circles), $500^{\circ} \mathrm{C}$ (squares), $600^{\circ} \mathrm{C}$ (crosses) and $800^{\circ} \mathrm{C}$ (triangles). For the low-temperature isothermal runs $\left(400\right.$ and $\left.500^{\circ} \mathrm{C}\right),{ }^{40} \mathrm{Ar}^{*}$ release is shown with solid circles and squares, whereas ${ }^{39} \mathrm{Ar}_{\mathrm{k}}$ is shown by open circles and squares. For the high-temperature isothermal runs $\left(600^{\circ} \mathrm{C}\right.$ and $\left.800^{\circ} \mathrm{C}\right)$, only ${ }^{40} \mathrm{Ar}^{*}$ is displayed because there are negligible differences between the two argon isotopes. Theoretical volume diffusion curves obtained from Eq. (1) for a cylindrical crystal with various $D / a^{2}$ values are also presented on the same diagram for comparison. The data for the $800^{\circ} \mathrm{C}$ isothermal runs exclude the argon released in the first two steps $\left(650^{\circ} \mathrm{C}\right.$ and $750^{\circ} \mathrm{C}$ - $30 \mathrm{~min} / \mathrm{step}$ ).
0.5-4 $\mathrm{h}$ for KM-500 and 0.5-11 $\mathrm{h}$ for CPC-500; the data from the later stages of isothermal heating for all of the samples form the second array. In each array, the $D / a^{2}$ values calculated from the release of ${ }^{39} \mathrm{Ar}_{\mathrm{K}}$ and ${ }^{40} \mathrm{Ar}^{*}$ are generally consistent with each other within $1 \sigma$. The mean $D / a^{2}$ for the first array is usually about 2-3 times higher than the second array. The CPC-400 run, however, only exhibits a single linear trend after $6 \mathrm{~h}$.

The time at which the transition occurs from the high-diffusivity linear trend to the lower-diffusivity linear trend varies between the runs (Fig. 7a-d). This transition point appears to be inversely correlated with the isothermal temperature for each sample, although it occurs roughly at the same cumulative fraction lost $F$. For instance, in the case of KM biotite, the change in $D / a^{2}$ occurs at $\sim 5 \%$ of the total ${ }^{39} \mathrm{Ar}_{\mathrm{K}}$ lost, while for CPC biotite, the transition takes place at $\sim 11 \%$ (Fig. $7 \mathrm{a}, \mathrm{b}$ and $\mathrm{d}$ ). This implies that a fixed amount of gas is lost faster than the gas released in the later stages of isothermal heating. If this is the case, then the CPC-400 run, which only shows a single linear trend on the $F$ vs. $t^{1 / 2}$ diagram (Fig. 7c), records degassing of only the first argon component, since the total amount of argon lost during the isothermal portion of the experiments was only $\sim 2.7 \%$ (Fig. 6b).

$D / a^{2}$ values for all high-temperature isothermal runs exponentially decrease with time (Fig. $7 \mathrm{e}-\mathrm{g}$ ). The $D / a^{2}$ decreases by about one order of magnitude in the KM-600 run and about 2 orders of magnitude in the $800^{\circ} \mathrm{C}$ isothermal runs.

\subsection{Argon release during step-heating}

The argon release patterns from the normal stepheating runs (KM-N and CPC-N) exhibit two main pulses of Ar release (Fig. 8a-d). The peak of first pulse is centered at $\sim 650^{\circ} \mathrm{C}$ for both biotite samples. The peak of the second pulse, however, appears

Fig. 5. ${ }^{40} \mathrm{Ar} /{ }^{39} \mathrm{Ar}$ release spectra for biotites isothermally heated for $\sim 44 \mathrm{~h}$ compared with the original biotite spectra (from normal step-heating). The $\mathrm{Ca} / \mathrm{K}$ ratio for each gas fraction is also shown in the same diagram. The original age spectra are outlined, whereas the age spectra from the corresponding isothermal run are plotted with two patterns: black — includes all steps obtained isothermally, shaded — includes the remaining steps obtained by incremental heating. 

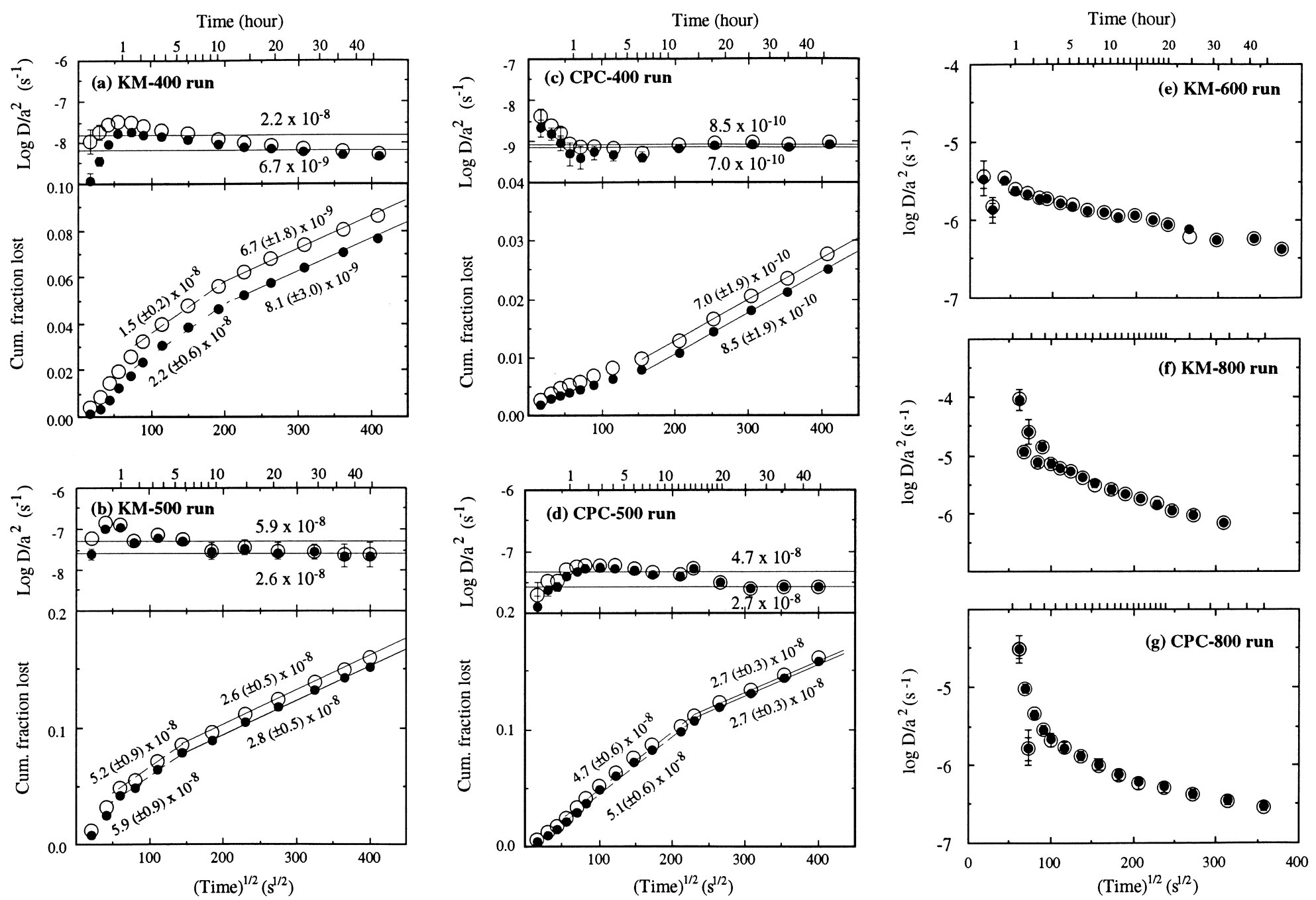

Fig. 7. Plots of $\log D / a^{2}$ and cumulative fraction lost vs. (time) $)^{1 / 2}$ for the low-temperature $\left(400^{\circ} \mathrm{C}\right.$ and $\left.500^{\circ} \mathrm{C}\right)$ isothermal runs (a-d) and plots of $\log D / a^{2}$ vs. (time $)^{1 / 2}$ for the high-temperature $\left(600^{\circ} \mathrm{C}\right.$ and $\left.800^{\circ} \mathrm{C}\right)$ runs $(\mathrm{e}-\mathrm{g})$. Open circles represent ${ }^{39} \mathrm{Ar}_{\mathrm{K}}$, whereas solid circles represent ${ }^{40} \mathrm{Ar}$. In the plots for the low-temperature isothermal runs (a-d), the solid line indicates the mean $D / a^{2}$ of all points in the second linear array, while the dashed line represents the mean $D / a^{2}$ of all points in the first array. Reference lines with different $D / a^{2}$ values are also shown in the $\log D / a^{2}$ vs. (time) $)^{1 / 2}$ plots for the low temperature runs for comparison. For a more detailed discussion of these arrays, please see text. 

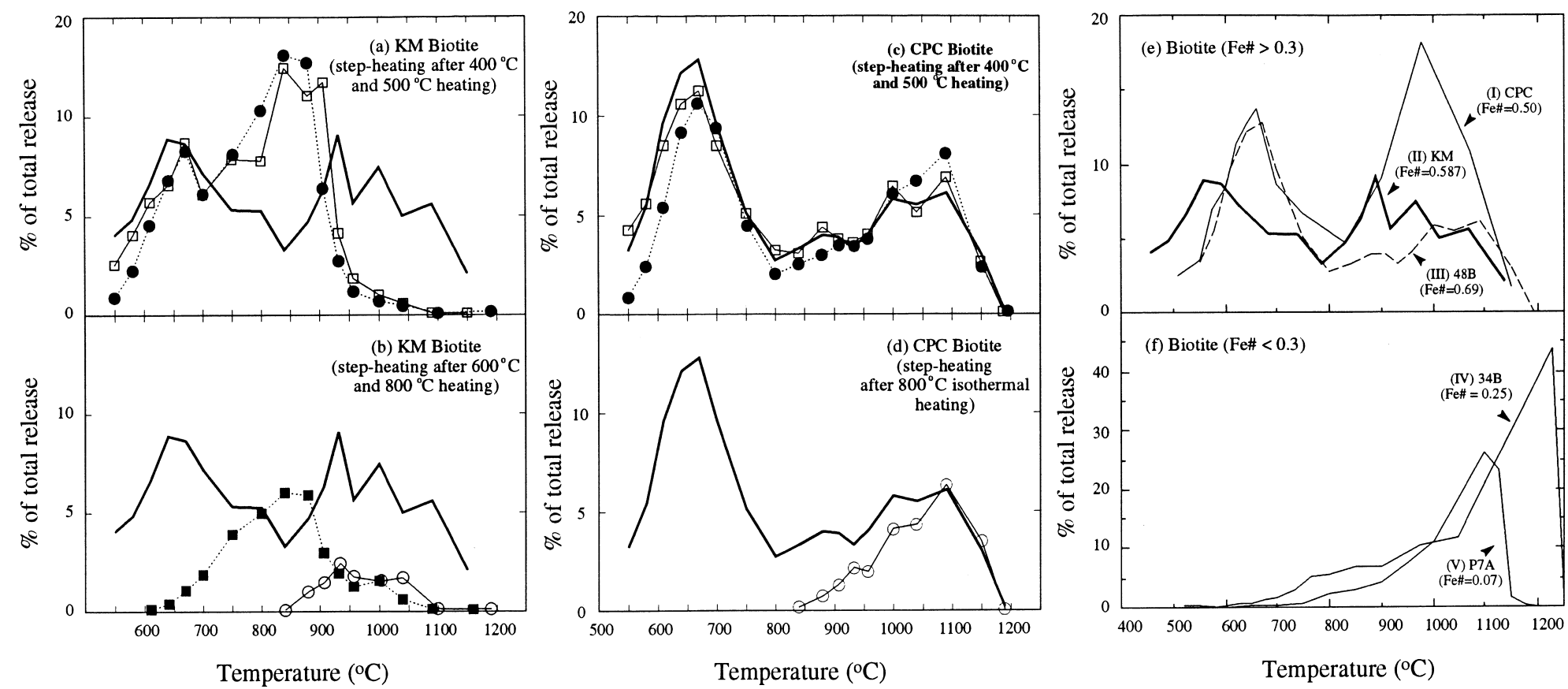

Fig. 8. Argon release from KM biotite ((a) and (b)) and CPC biotite ((c) and (d)) during step-heating after the isothermal runs. Solid circles, blank squares, solid squares and blank circles represent the $400^{\circ} \mathrm{C}, 500^{\circ} \mathrm{C}, 600^{\circ} \mathrm{C}$ and $800^{\circ} \mathrm{C}$ isothermal heating runs, respectively. In (a)-(d), the original release pattern (from normal step-heating) is shown as a thick line. For comparison, the representative ${ }^{39} \mathrm{Ar}_{\mathrm{K}}$ release patterns for a variety of trioctahedral micas with $\mathrm{Fe} /(\mathrm{Fe}+\mathrm{Mg}$ ) $>0.30$ and $<0.30$, are compiled in (e) and (f), showing the compositional effects on reaction-enhanced argon release. Data sources for (e) and (f): (I) CPC and (II) KM: this study; (III) 48B and (IV) 34B: Onstott et al. (1989); P7A: Phillips and Onstott (1988). 
to be inversely correlated with the $\mathrm{Fe} /(\mathrm{Fe}+\mathrm{Mg})$ ratio of each biotite; the second pulse is centered at $\sim 950^{\circ} \mathrm{C}$ for $\mathrm{KM}$ biotite $\left(\mathrm{Fe}^{\#}=0.87\right)$ and at $~$ $1050^{\circ} \mathrm{C}$ for $\mathrm{CPC}$ biotite $\left(\mathrm{Fe}^{\#}=0.50\right)$.

After isothermal heating, all of the biotites were incrementally heated following a fixed temperature/ time schedule. As shown in Fig. 8a and c, after isothermal heating at $400^{\circ} \mathrm{C}$ and $500^{\circ} \mathrm{C}$ for about 44 $\mathrm{h}$, the argon release patterns for both biotites still display two pulses, although the second pulse of KM biotite is shifted to a distinctly lower temperature $\left(\sim 850^{\circ} \mathrm{C}\right)$ and includes a larger proportion of gas. The release pattern of CPC biotite does not appear to be affected by the isothermal heating. Isothermal heating at $600^{\circ} \mathrm{C}$ and $800^{\circ} \mathrm{C}$ appears to result in the loss of the first pulse of gas in both biotites, although the second pulse is still present with proportionally less gas (Fig. 8b and d).

\section{Argon release mechanisms}

To explain the above observations, two factors must be considered: (1) the potential sites where Ar can reside in the biotite crystals, and (2) the possible mechanisms involved in releasing $\mathrm{Ar}$ from these sites.

\subsection{Possible Ar retention sites}

Given that the recoil energy of ${ }^{39} \mathrm{Ar}_{\mathrm{K}}$ (from neutron irradiation) is $\sim 300 \mathrm{keV}$ and ${ }^{40} \mathrm{Ar}^{*}$ (from natural decay) is $\sim 28 \mathrm{eV}$, these energies are sufficient for an argon atom to be displaced from its parent $\mathrm{K}$ (which is located in biotite interlayer sites) and to penetrate the biotite layer structure (Brandt and Voronovskiy, 1967; Turner and Cadogan, 1974; Onstott et al., 1995). In addition, if there are some defects (i.e., vacancies or dislocations) present in the structure, Ar atoms would preferentially occupy these defect sites (Norgett and Liaiard, 1968; Reed, 1977). Natural biotites also contain other numerous structural defects due to (1) crystal growth or deformation in the natural environment (Bell and Wilson, 1981), (2) neutron irradiation in the reactor and the natural decay of radioactive nuclides (Bonfiglioli et al., 1961; Price and Walker, 1962; Itoh and Tanimura, 1986; Tseng et al., 1995), and (3) sample preparation (mechanical crushing and grinding) which can potentially damage the crystal structure (MacKenzie, 1953; Gerling et al., 1966; Fechtig and Kalbitzer, 1966; Meike, 1989). Thus, Ar atoms are expected to be homogeneously distributed throughout the entire crystal structure, but will preferentially concentrate in any structural defects. In addition, any atmospheric argon component is likely to be concentrated in these structural defects, since they could act as pathways for relatively rapid argon migration into the crystal.

\subsection{Defect-enhanced or short-circuit diffusion}

The release curves of the low-temperature isothermal runs $\left(400^{\circ}-500^{\circ} \mathrm{C}\right)$ reflect a relatively constant $D / a^{2}$ over most of the duration of the experiment with anomalously high $D / a^{2}$ values in the initial stages of heating (Fig. 7). This pattern of release is very similar to the argon released from $\mathrm{KCl}$ in isothermal experiments reported by Fechtig and Kalbitzer (1966), which they attributed to enhanced diffusion via structural defects. Not only are dislocations energetically favoured as traps for argon relative to the crystal structure, but they can also enhance the diffusion rate by means of fast-transport mechanisms (Yund et al., 1981; Le Claire and Rabinovitch, 1984). ${ }^{36} \mathrm{Ar}$ is the primary indicator of potential atmospheric contamination in crystals, where it would be expected to be found loosely held in extended defects and defect structures. Fig. 9 shows that most of the ${ }^{36} \mathrm{Ar}$ in the samples is released in the first $30 \mathrm{~min}$ to one hour and is associated with high values of $D / a^{2}$ in the initial stages of heating (Fig. 7). Thus, existing defects likely play an important role in the low- $T$ release of Ar from biotite in vacuo.

Although the detailed transport mechanisms by which Ar moves through a crystal structure are still unknown, there are several defect-related transport mechanisms which are much more rapid than solidstate volume diffusion. More specifically, many studies (e.g., Hart, 1957; Harrison, 1961; Aifantis, 1979; Yund et al., 1981; Le Claire and Rabinovitch, 1984, and references therein) have suggested and demonstrated that extended defects (such as dislocations, micropores, microfractures, etc.) within individual crystals may serve as preferential pathways for the rapid transport of migrating species. The enhanced 


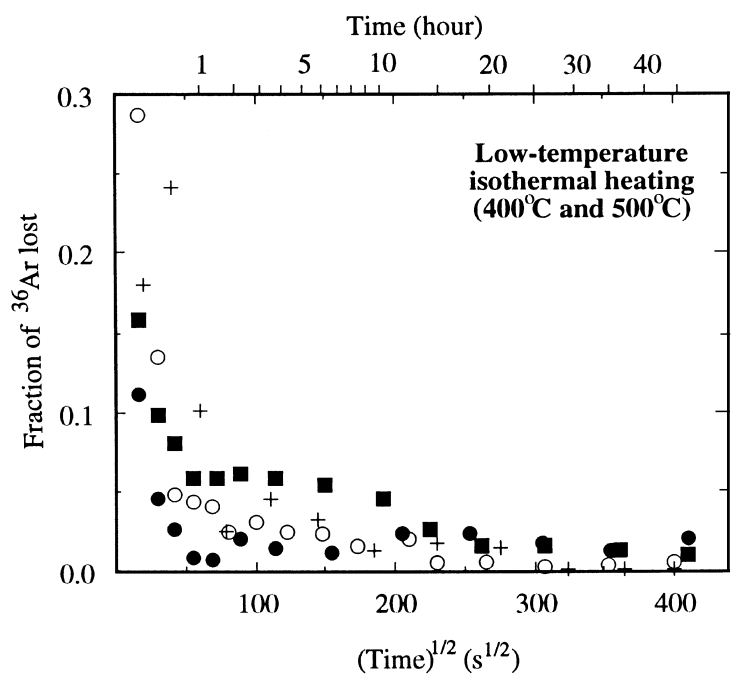

Fig. 9. Fraction of ${ }^{36} \mathrm{Ar}$ release vs. (time) ${ }^{1 / 2}$ for the low-temperature isothermal heating runs. Most of the ${ }^{36} \mathrm{Ar}$ was released during the first 30-60 min period of isothermal heating. Solid circles represent the data collected in the CPC-400 run; open circles, CPC-500; solid squares, KM-400; crosses, KM-500.

transport along any such defects may be termed "short-circuit" (SC) diffusion, and the combined interaction of solid-state volume diffusion coupled with SC diffusion is known as multipath diffusion (Lee, 1993, 1995).

Lee $(1993 ; 1995)$ suggested that because of the relatively large size of the $\mathrm{Ar}$ atom $(1.9 \AA)$ in relation to the crystal lattice spacings of most silicates, SC diffusion may be an important mode of $\mathrm{Ar}$ transport if extended defects are present. In addition to explaining discrepant diffusion data in the bulk $\mathrm{Ar}$ diffusion experiments from hornblende (Harrison, 1981) and biotite (Harrison et al., 1985), Lee (1993; 1995) demonstrated that a multipath diffusion mechanism could explain the pattern of low-temperature Ar release of hornblende in in vacuo isothermal experiments. As a result, the low $-T\left(400\right.$ and $\left.500^{\circ} \mathrm{C}\right)$ isothermal experiments in Fig. 7a-d were modelled using the multipath diffusion model of Lee and Aldama (1992). Input parameters to the model were derived from estimates of the volume-diffusion parameters of Ar in biotite (Giletti, 1974; Norwood, 1974; Harrison et al., 1985; Grove and Harrison, 1996), and the SC diffusion parameters of Lee (1993). The model parameters are given in Table 2 and the results of the modelling are shown in Fig. 10. In all cases, the model provides an adequate fit to the data.

There are a number of important points to note from Table 2. First, the SC diffusion coefficients

Table 2

Multipath diffusion model parameters for low-temperature runs

\begin{tabular}{|c|c|c|c|c|c|c|c|}
\hline & \multicolumn{4}{|c|}{ KM biotite } & \multicolumn{3}{|c|}{ CPC biotite } \\
\hline & \multicolumn{2}{|l|}{$400^{\circ} \mathrm{C}$} & \multicolumn{2}{|l|}{$500^{\circ} \mathrm{C}$} & \multicolumn{2}{|l|}{$400^{\circ} \mathrm{C}$} & \multirow{2}{*}{$\frac{500^{\circ} \mathrm{C}}{\mathrm{Ar}}$} \\
\hline & ${ }^{39} \mathrm{Ar}_{\mathrm{K}}$ & ${ }^{40} \mathrm{Ar}^{*}$ & ${ }^{39} \mathrm{Ar}_{\mathrm{K}}$ & ${ }^{40} \mathrm{Ar}^{*}$ & ${ }^{39} \mathrm{Ar}_{\mathrm{K}}$ & ${ }^{40} \mathrm{Ar}^{*}$ & \\
\hline Radius ( $\mu \mathrm{m})$ & 96.5 & 96.5 & 96.5 & 96.5 & 108.5 & 108.5 & 108.5 \\
\hline$\kappa_{1}\left(\times 10^{-7} \mathrm{~s}^{-1}\right)$ & 0.4 & 0.4 & 0.5 & 0.5 & - & - & 0.5 \\
\hline \multicolumn{8}{|c|}{ High-diffusivity / short-circuit (SC) paths: } \\
\hline$c_{1}($ initial $)(\%)^{\mathrm{b}}$ & 3.8 & 2.9 & 4.5 & 4.0 & $<1.0$ & $<1.0$ & 6.0 \\
\hline$D_{\mathrm{sc}}=D_{1}\left(\times 10^{-10} \mathrm{~s}^{-1}\right)$ & 14 & 12 & 80 & 60 & - & - & 8 \\
\hline \multicolumn{8}{|l|}{ Crystal lattice: } \\
\hline
\end{tabular}

Cylindrical geometry assumed for all runs, using a fully implicit numerical scheme, 1001 spatial nodes, and 2025 time steps of $100 \mathrm{~s}$ each.

${ }^{\mathrm{a}}$ Volume fraction of high-diffusivity pathways.

${ }^{\mathrm{b}}$ Concentrations are normalized so that total concentration $c=c_{1}+c_{2}=1$. 

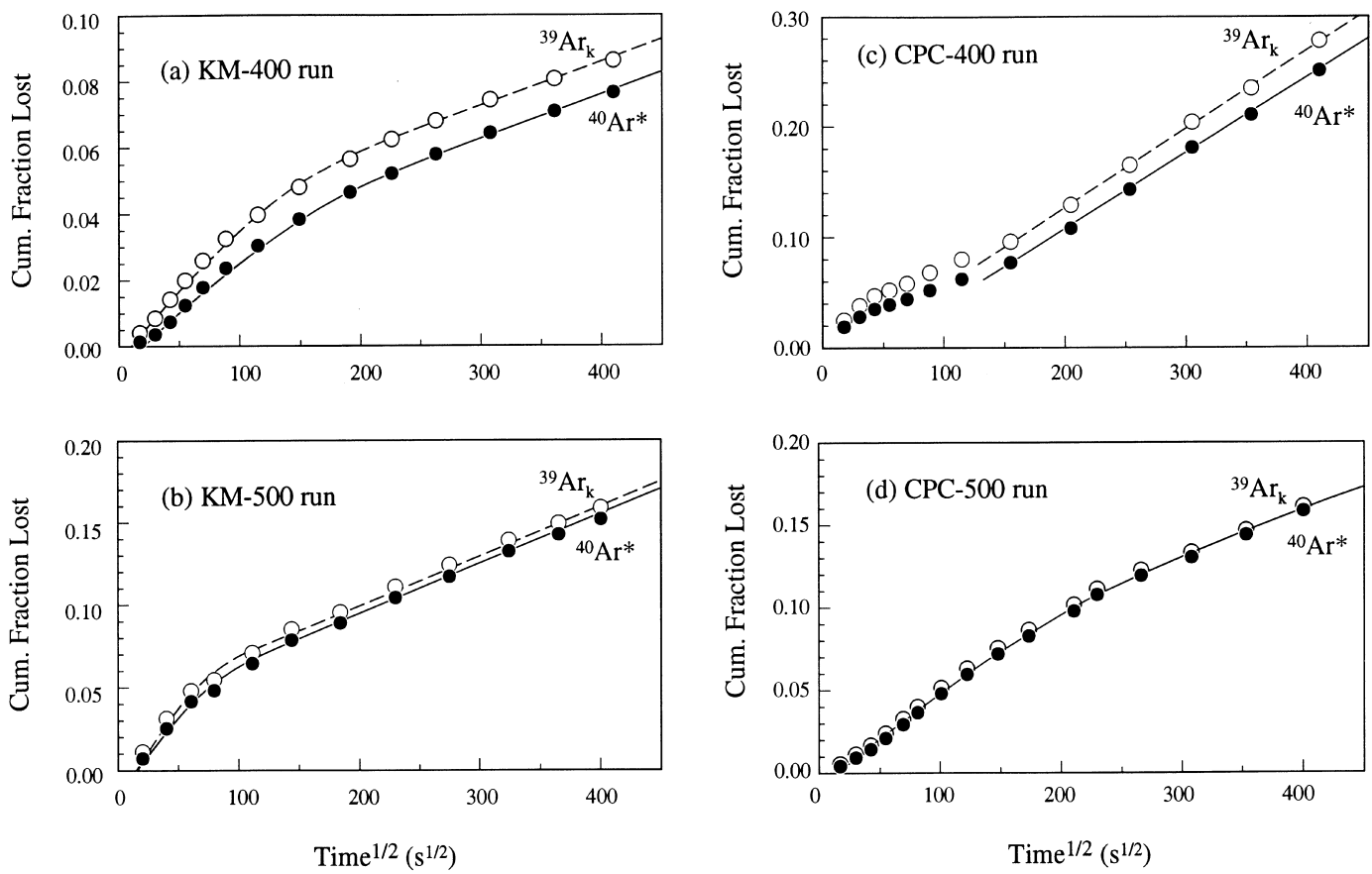

Fig. 10. Results of multipath diffusion modelling for low-temperature isothermal runs at 400 and $500^{\circ} \mathrm{C}$. Open and solid circles represent the experimental data for ${ }^{39} \mathrm{Ar}_{\mathrm{K}}$ and ${ }^{40} \mathrm{Ar}$, respectively. The experimental data can be explained adequately by coupling enhanced diffusion along extended defects (short-circuit diffusion) with a volume-diffusion mechanism, as proposed in a multipath diffusion model. Model parameters are given in Table 2.

used in the model are several orders of magnitude higher than the respective volume-diffusion coefficients. This is consistent with the experimental findings of several other studies of SC diffusion (e.g., Yund et al., 1981; Yurimoto et al., 1989; Lee, 1993). Second, all runs except the CPC biotite at $400^{\circ} \mathrm{C}$ show release patterns reflecting $\mathrm{SC}$-controlled diffusion at early times followed by volume-diffusion release at later times in the same experiment. This type of behavior is consistent with the notion that any Ar trapped in SC paths will be released relatively quickly, since SC-diffusion coefficients are several orders of magnitude greater than corresponding volume-diffusion coefficients. At $400^{\circ} \mathrm{C}$, the $\mathrm{Ar}$ release patterns from CPC biotite are consistent with release via a single diffusion mechanism (Fig. 7c), and modelling the linear segments of the curves yields diffusion coefficients consistent with those expected from Ar released via volume diffusion (Table 2). Third, the model curves require that a small fraction of the Ar must be located initially in the high-diffusivity pathways - a phenomenon which can be explained by the structural decomposition mechanisms discussed previously. At temperatures below the decomposition temperatures of the biotite samples, Fe oxidation and dehydrogenation are still taking place. Because the oxidation of $\mathrm{Fe}^{2+}$ to $\mathrm{Fe}^{3+}$ distorts the biotite structure, defects would be expected to nucleate throughout the lattice. As suggested by Lee (1993), such defects could act as preferential trapping sites for Ar, retaining Ar atoms until either the thermal energy is high enough or times are long enough for the Ar to diffuse through a well-connected network of SC paths. Moreover, structural decomposition would also explain why the amount of Ar initially in the SC paths appears to increase with increasing temperature in both $\mathrm{KM}$ and CPC biotites. Although the amount of Ar initially sited in the SC paths in KM biotite $(\sim 3-4.5 \%)$ is identical to that estimated by Lee (1993) in the coexisting hornblende, $c_{1}$ in $\mathrm{KM}$ biotite is $2.9-3.8 \%$ at $400^{\circ} \mathrm{C}$ but $4.0-4.5 \%$ at $500^{\circ} \mathrm{C}$ (Table 2); a similar 
trend is observed for CPC biotite. Higher temperatures would result in a greater degree of Fe-oxidation and dehydroxylation and therefore, a concomitant increase in the defect density.

One notable phenomenon from Fig. 10 is the relationship between the ${ }^{39} \mathrm{Ar}$ and ${ }^{40} \mathrm{Ar}$ release patterns in the same experiment. In all cases, the release patterns of both isotopes are strongly correlated, although ${ }^{39} \mathrm{Ar}$ always appears to be released faster than ${ }^{40} \mathrm{Ar}$ in the early steps of the experiment. Although both ${ }^{39} \mathrm{Ar}$ and ${ }^{40} \mathrm{Ar}$ are generated from $\mathrm{K}$, the greater recoil distance for ${ }^{39} \mathrm{Ar}$ resulting from the ${ }^{39} \mathrm{~K}(n, p){ }^{39} \mathrm{Ar}$ reaction suggests that ${ }^{39} \mathrm{Ar}$ would not necessarily remain in the same lattice site as radiogenic ${ }^{40} \mathrm{Ar}$ (Turner and Cadogan, 1974; Onstott et al., 1995). Although the effects of neutron irradiation damage in biotite have not been studied to date, it is well known that radiation damage can enhance mass transport in solids (e.g., Borge and Dienes, 1988) and that some minerals (e.g., biotite) are particularly susceptible to artificial radiation damage (e.g., Bell and Wilson, 1977; Tseng et al., 1995). Thus, the most significant crystallographic effect of neutron irradiation on biotite is most likely to be the production of extended defects in lattice. Because of the large size of the Ar atom and concomitant energy considerations, Lee (1995) suggested that Ar will prefer to reside in structural defects. If so, then ${ }^{39} \mathrm{Ar}$ recoiled from ${ }^{39} \mathrm{~K}$ may be located preferentially in irradiation-damage defects as well as defects found naturally in the crystal. From the model parameters in Table 2, both the ${ }^{39} \mathrm{Ar}$ SC diffusion coefficient $\left(D_{\mathrm{sc}}\right)$ and ${ }^{39} \mathrm{Ar}$ initial concentration in the SC paths $\left(c_{1}\right)$ are higher than the corresponding ${ }^{40} \mathrm{Ar}$ SC diffusion coefficient and initial concentration at the same temperature for all samples. The higher initial concentrations and SC diffusivities of ${ }^{39} \mathrm{Ar}$ in comparison to ${ }^{40} \mathrm{Ar}$ agree with this idea, and indicate that neutron irradiation may influence Ar release at very low temperatures. This effect is expected to decrease significantly or disappear altogether at higher temperatures, since such defects would anneal with increasing temperature within a period of a few tens of minutes (Bonfiglioli et al., 1961; Meike, 1989). Indeed, differences between ${ }^{39} \mathrm{Ar}$ and ${ }^{40} \mathrm{Ar}$ release in each of the $\mathrm{KM}$ and $\mathrm{CPC}$ biotite runs are observed to be much less at $500^{\circ} \mathrm{C}$ than at $400^{\circ} \mathrm{C}$. It should be noted that the production of small-scale defects due to Fe-oxidation and dehydroxylation (see Section 6.3) with increasing temperature may be offset eventually by the annealing of these defects (as well as irradiation-induced defects) at elevated temperatures. Although the evidence for enhanced Ar release in biotite via irradiation-induced defects is not definitive, all of the above observations are consistent with this hypothesis.

The relationship between the exchange coefficients, $\kappa_{1}$ and $\kappa_{2}$, and the Ar partition coefficient $k^{*}$ between the crystal and SC paths can be used to estimate the volume fraction $f$ of high-diffusivity paths in the crystal, using Eq. 4.11 of Aifantis (1979). Onstott et al. (1991) estimate partition coefficients as high as 333 for Ar between a coexisting fluid and biotite. Assuming that this is probably a minimum value for $\mathrm{Ar}$ partitioned between voids /vacancies (i.e., the SC paths) and the crystal, the model parameters yield a maximum estimate of the volume fraction of SC paths of around 0.003, which is not unreasonable. Lee (1993) and Sletten and Onstott (1998) suggested that one important factor which may also contribute to increased defect densities is the thermal oxidation/dehydrogenation process during heating in vacuo, which could create point/extended defects throughout the crystal lattice.

The multipath diffusion model may also explain why the calculated in vacuo volume diffusion coefficients $\left(D_{\mathrm{v}}\right)$ are 1-2 orders of magnitude higher than those of Norwood (1974), Harrison et al. (1985), and Grove and Harrison (1996). As demonstrated by Sanz et al. (1983) and Rebbert (1986), the preferential ordering of cations during thermal oxidation suggests that cations in the biotite structure are at least locally mobile, so that an increased defect density may be associated with the conversion of biotite to oxybiotite. The resultant increase in the number of SC pathways implies that SC diffusion would be the dominant diffusive process at low temperatures and would enhance the bulk Ar diffusivity in the biotite. Consequently, the volume diffusivities $\left(D_{\mathrm{v}}\right)$ calculated from the latter steps of the low-temperature isothermal runs may not be strictly representative of a true volume-diffusion process, but may be bulk diffusivities reflecting Ar release via multipath diffusion.

It is also of interest to compare the argon diffusivity of biotite in vacuo with the diffusivities derived 
from hydrothermal experiments on biotites with varying composition (Giletti, 1974; Norwood, 1974; Harrison et al., 1985; Grove and Harrison, 1996). In general, the argon diffusivity in biotite appears to be empirically correlated with the $\mathrm{Fe} /(\mathrm{Fe}+\mathrm{Mg})$ ratio of the mineral (Onstott et al., 1989), as predicted in the ionic porosity model of Dahl (1994). Using the interpolation scheme proposed by Onstott et al. (1989), in which both the pre-exponential frequency factor $\left(D_{0}\right)$ and the activation energy $(E)$ of argon diffusion are functions of the $\mathrm{Fe} /(\mathrm{Fe}+\mathrm{Mg})$ value, $\mathrm{KM}$ biotite $\left(\mathrm{Fe}^{\#}=0.87\right)$ and $\mathrm{CPC}$ biotite $\left(\mathrm{Fe}^{\#}=\right.$ 0.50 ) should have activation energies of 40.5 $\mathrm{kcal} /$ mole and $47.9 \mathrm{kcal} /$ mole, respectively. The estimated $D_{0}$ for KM biotite is either $0.00052 \mathrm{~cm}^{2} / \mathrm{s}$ (by interpolating the data of Giletti (1974) and Norwood (1974) $(\mathrm{G}$ and $\mathrm{N})$ ) or $0.01938 \mathrm{~cm}^{2} / \mathrm{s}$ (by interpolating the data of Giletti (1974), Harrison et al. (1985) and Grove and Harrison (1996) (G and H)). For CPC biotite, $D_{0}$ should be either 0.01161 $\mathrm{cm}^{2} / \mathrm{s}$ or $0.0989 \mathrm{~cm}^{2} / \mathrm{s}$, respectively.

Based on these parameters, theoretical $D / a^{2}$ values were calculated at temperatures from 300 $1000^{\circ} \mathrm{C}$ for each biotite sample, assuming various $a$ values, and plotted on Arrhenius diagrams with the calculated mean $D / a^{2}$ values for the corresponding isothermal runs (Fig. 11). From the figure, it is clear that the $D / a^{2}$ values calculated from the later stages of the low-temperature isothermal runs (as shown in Fig. 7) are about 2-4 orders of magnitude higher than those obtained from the hydrothermal diffusion data (shown as shaded areas in Fig. 11).

The most obvious cause for this discrepancy is a difference in the effective diffusion dimension $a$. Assuming this discrepancy is the sole result of $a$, then these $D / a^{2}$ values yield an effective radius of diffusion equal to $1-15 \mu \mathrm{m}$ which is much smaller than the 64-225 $\mu \mathrm{m}$ values reported by Norwood (1974), Harrison et al. (1985) and Wright et al. (1991). This range of $a$, however, is consistent with an increase in defect density (i.e., SC pathways) as the mineral grains are heated. With the formation of additional SC pathways and networks throughout the crystal structure, the enhanced Ar release rate would be similar to that expected from a much smaller diffusion domain.

\subsection{Reaction-enhanced release of argon}

In Figs. 6 and 7, it is evident that the argon released from biotites during high-temperature

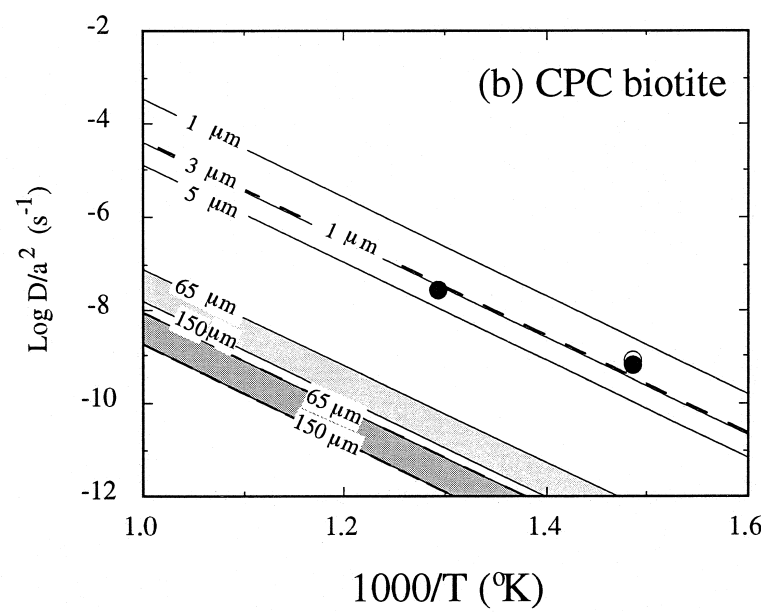

Fig. 11. Comparison of $D / a^{2}$ for argon diffusion during the in vacuo low-temperature isothermal heating (circles) with $D / a^{2}$ values (shown as lines for a range of values) derived from Ar diffusion data interpolated from published experimental results. See text for discussion and the interpolation method. Solid lines utilize the $D_{0}$ value interpolated from the data of Giletti (1974), Harrison et al. (1985) and Grove and Harrison (1996), while dashed lines use $D_{0}$ values obtained from interpolating the data of Giletti (1974) and Norwood (1974). The shaded areas mark the possible ranges of the argon diffusivity of biotite with characteristic diffusion radius of $65-150 \mu \mathrm{m}$, as suggested by Norwood (1974) and Harrison et al. (1985). 
isothermal heating $\left(>600^{\circ} \mathrm{C}\right)$ is not controlled by a simple volume-diffusion mechanism, as reflected in the rapid loss of argon and the substantial decrease of $D / a^{2}$ with time. Gaber et al. (1988) observed similar features for a biotite heated at $\sim 800^{\circ} \mathrm{C}$ in vacuo, and suggested that the rate of argon release from biotite at high-temperatures could be controlled by some process related to phase changes within the mineral. Indeed, both biotites in this study appear to have experienced complicated structural changes, as demonstrated by the HTXRD and SEM results (Figs. 2-4).

The reduction of all cell parameters at elevated temperatures is consistent with the replacement of biotite with oxybiotite, through dehydrogenation, dehydroxylation and the oxidation of Fe (Wones, 1963; Ohta et al., 1982; Rebbert, 1986; Ferrow, 1987). In general, two types of oxidation are thought to occur in biotites when heated (Vedder and Wilkins, 1969; Rouxhet et al., 1972; Sanz et al., 1983; Rebbert, 1986). Thermal oxidation occurs when iron reacts with hydroxyl ions in the biotite structure due to the thermally-induced decomposition, i.e., $2 \mathrm{Fe}^{+2}+$ $2 \mathrm{OH}^{-} \rightarrow 2 \mathrm{Fe}^{+3}+2 \mathrm{O}^{-2}+\mathrm{H}_{2}$. Chemical oxidation occurs when iron reacts with both free oxygen and/or the hydroxyl ions during heating, i.e., $4 \mathrm{Fe}^{+2}+$ $4 \mathrm{OH}^{-}+\mathrm{O}_{2} \rightarrow 2 \mathrm{H}_{2} \mathrm{O}+4 \mathrm{Fe}^{+3}+4 \mathrm{O}^{-2}$ or $\mathrm{Fe}^{+2}+$ $1 / 4 \mathrm{O}_{2} \rightarrow \mathrm{Fe}^{+3}+1 / 2 \mathrm{O}^{-2}$. Thermal oxidation generally takes place at temperatures of $600-800^{\circ} \mathrm{C}$ and results in weight loss, whereas chemical oxidation generally takes place at lower temperatures (400$600^{\circ} \mathrm{C}$ ) and results in weight gain (Rouxhet et al., 1972; Sanz et al., 1983). The temperature range over which the cell parameters decrease in this study $\left(600-850^{\circ} \mathrm{C}\right.$, Figs. 2 and 3 ), in addition to the weight-loss data discussed previously, strongly suggests that thermal oxidation is probably the dominant process affecting biotites heated in vacuo.

Previous IR and Mössbauer studies indicate that biotite heated at elevated temperatures will experience a series of decomposition reactions, including dehydroxylation, dehydrogenation and oxidation, associated with the appearance of such decomposition products as $\alpha-\mathrm{Fe}_{2} \mathrm{O}_{3}$ and amorphous materials (Vedder and Wilkins, 1969; Rouxhet et al., 1972; Tripathi et al., 1978; Bagin et al., 1980; Sanz et al., 1983; Ferrow, 1987). These processes usually occur in three stages: (a) release of $\mathrm{OH}^{-}$groups $\left(\right.$as $\left.\mathrm{H}_{2} \mathrm{O}\right)$ associated with two cations and one vacancy at temperatures between $600-800^{\circ} \mathrm{C}$; this becomes negligible below $600^{\circ} \mathrm{C}$; (b) oxidation of $\mathrm{Fe}^{+2}$ to $\mathrm{Fe}^{+3}$ with simultaneous loss of hydrogen or hydroxyl ions from $600-800^{\circ} \mathrm{C}$ (thermal oxidation); and (c) loss of $\mathrm{OH}^{-}$groups close to the octahedral sites $-3 \mathrm{Mg}^{+2}$, $2 \mathrm{Mg}^{+2} \mathrm{Fe}^{+3}$ and $\mathrm{Mg}^{+2} 2 \mathrm{Fe}^{+3}$ - around $1000^{\circ} \mathrm{C}$ before or during the final decomposition of biotite. The structural changes involved in the transformation of biotite to oxybiotite include flattening of octahedral sites, rotation of tetrahedral sites and distortion of interlayer sites in the biotite structure (Hazen and Wones, 1972, 1978; Ohta et al., 1982). In addition, the generation of $\mathrm{H}_{2}$ and $\mathrm{H}_{2} \mathrm{O}$ after dehydroxylation and dehydrogenation, as well as the structural distortion due to Fe-oxidation, dehydroxylation and dehydrogenation, will cause internal stress within the phyllosilicate structures, potentially causing the structural delamination in biotite, as observed in Fig. 4 (Vedder and Wilkins, 1969; Stucki et al., 1984; Catti et al., 1989; Wu et al., 1989).

Argon retained in the crystal is held essentially by the ionic bonds of the surrounding ions, since the Van der Waals bonds between Ar and other elements are too weak to prevent argon escape from the mica structure (Sardarov, 1961; Dahl, 1994). In this case, the irreversible destruction of the biotite structure (through the breaking of chemical bonds and subsequent delamination) could result in the rapid escape of $\mathrm{Ar}$ atoms from the crystal. Delamination would not only lead to the loss of argon residing in the interlayer sites, but would also result in a reduction in the characteristic dimension for argon diffusion. Consequently, even though small-scale (e.g., lattice) defects would be expected to anneal out at elevated temperatures, significantly enhanced diffusion would be expected for argon released from biotite at temperatures above its stability field due to the delamination process, as observed in Figs. 6 and 7. A similar phenomenon has also been found in hornblende and muscovite (Lee, 1993; Sletten and Onstott, 1998).

The correlation of Ar release with the decomposition of the biotite structure implies that the number of argon release pulses in a typical step-heating run should be determined by the number of octahedral environments for the $\mathrm{OH}^{-}$ions, and the fractional loss of Ar should approximately reflect the volume 
fraction of biotite structure that has decomposed, i.e., Ar release at high temperatures will be a function of biotite composition and the abundance of octahedral vacancies. There are at least five possible octahedral cation configurations surrounding $\mathrm{OH}^{-}$in the biotite structure: $\mathrm{OH}^{-}-3 \mathrm{Mg}^{+2}, \mathrm{OH}^{-}-2 \mathrm{Mg}^{+2} \mathrm{Fe}^{+2}, \mathrm{OH}^{-}$ $\mathrm{Mg}^{+2} 2 \mathrm{Fe}^{+2}, \mathrm{OH}^{-}-3 \mathrm{Fe}^{+2}, \mathrm{OH}-2 \mathrm{R}^{+2} \square$ (where $\mathrm{R}$ represents the cation, and $\square$ indicates a vacancy). As discussed above, the decomposition of biotite first proceeds by the loss of $\mathrm{OH}^{-}$near vacancies and $\mathrm{Fe}$ cations between $600-800^{\circ} \mathrm{C}$, followed by the loss of the rest of the $\mathrm{OH}^{-}$near $3 \mathrm{Mg}^{+2}, 2 \mathrm{Mg}^{+2} \mathrm{Fe}^{+3}$ and $\mathrm{Mg}^{+2} 2 \mathrm{Fe}^{+3}$ at around $1000^{\circ} \mathrm{C}$. Thus, two pulses of argon release centered around these temperature ranges $\left(600-800^{\circ} \mathrm{C}\right.$, and $\left.\sim 1000^{\circ} \mathrm{C}\right)$ would be expected for the ${ }^{40} \mathrm{Ar} /{ }^{39} \mathrm{Ar}$ step-heating of biotite. On the other hand, because there is only one type of octahedral configuration for $\mathrm{OH}^{-}$in phlogopite, i.e., $\mathrm{OH}^{-}-3 \mathrm{Mg}^{+2}$, only one argon release pulse is expected. Fig. 8 also includes a compilation of $\mathrm{Ar}$ release data from biotite and phlogopites obtained in other studies (Fig. 8e-f). The release patterns of the previously published biotite data and the biotite samples in this study $\left(\mathrm{Fe}^{\#}>0.5\right)$, [which display two pulses centered at $\sim 650^{\circ} \mathrm{C}$ and $950-1050^{\circ} \mathrm{C}$ (Fig. $8 \mathrm{a}-\mathrm{e})$ ], in addition to the phlogopite data [which only show a single release pulse at $950-1050^{\circ} \mathrm{C}$ (Fig. 8f)], are consistent with this hypothesis. Thus, the loss of argon at high temperatures $\left(>600^{\circ} \mathrm{C}\right)$ must be controlled by the decomposition processes, i.e., reaction-enhanced diffusion.

This hypothesis may also explain why the temperature range of the second Ar release pulse for the more Fe-rich KM biotite is lower than that for the CPC biotite (Fig. 8a-d). Because the loss of $\mathrm{OH}^{-}$ near the $\mathrm{Fe}^{+3}$ rich sites is likely to be easier than the loss of $\mathrm{OH}^{-}$near $\mathrm{Mg}^{+2}$-rich sites (due to the additional effects of Fe oxidation), (Vedder and Wilkins, 1969; Hazen and Wones, 1972, 1978; Ferrow, 1987), this would lower the stability field of biotite resulting in lower temperatures of Ar release.

It is well-known that the decomposition reactions of phyllosilicates are both temperature and time-dependent (Kodama and Brydon, 1968; Brindley and Lemaitre, 1987; Malhotra and Ogloza, 1989; Sletten and Onstott, 1998). With the gradual formation of oxybiotite as the biotite begins to decompose, the effect of reaction-enhanced diffusion on Ar release would be expected to decrease. This is consistent with the observation that $D / a^{2}$ values in the hightemperature isothermal runs exponentially decrease with time (Fig. 7e-f). Although it is possible that after very long times, Ar release from the partially decomposed biotite may eventually reflect a volume-diffusion process, the utility of any diffusion coefficient calculated from such data is questionable, as it characterizes argon release from a crystal structure significantly different from true biotite.

\section{Implications for disturbed apparent age spectra}

The above considerations can also explain some of the causes for the formation of disturbed age spectra. In the age spectra for the biotites (Fig. 5), the first few percent of ${ }^{39} \mathrm{Ar}_{\mathrm{K}}$ released in the $400^{\circ} \mathrm{C}$ and $500^{\circ} \mathrm{C}$ runs yield young dates. By examining the corresponding $D / a^{2}$ values for ${ }^{39} \mathrm{Ar}_{\mathrm{K}}$ and ${ }^{40} \mathrm{Ar}^{*}$, however, the release rate of ${ }^{39} \mathrm{Ar}_{\mathrm{K}}$ during this portion of the experiment was much faster than ${ }^{40} \mathrm{Ar} *$, although this difference diminishes with time (Figs. 7 and 10). According to volume-diffusion theory, the young dates could result from a depletion of ${ }^{40} \mathrm{Ar}^{*}$ along the grain margins. An alternative explanation, however, is that this phenomenon arises because of differences in the release of ${ }^{39} \mathrm{Ar}_{\mathrm{K}}$ residing in various defects vs. that in the crystal structure. If a biotite crystal contains a number of structural defects before neutron irradiation, argon residing in these structural defects is probably dominated by atmospheric argon with a negligible amount of radiogenic ${ }^{40} \mathrm{Ar}$ (e.g., Figs. 7, 9 and 10). During neutron irradiation, ${ }^{39} \mathrm{Ar}$ can be implanted into these structural defects through recoil. The argon residing in these structural defects will be first released via SC diffusion during the early stages of in vacuo heating, and will have low ${ }^{40} \mathrm{Ar} * /{ }^{39} \mathrm{Ar}$ ratios, resulting in young apparent ages.

Similarly, if there was excess argon present in these structural defects, the resulting age spectra should exhibit anomalously old dates in the early heating steps. This might explain the age spectrum of a hydrothermally treated biotite (Cooma biotite) reported by Harrison et al. (1985). Before hydrothermal treatment, the biotite separate yielded a flat age 
spectrum with a plateau date consistent with the $\mathrm{K}-\mathrm{Ar}$ date $(399.8 \mathrm{Ma}$ ), indicating a homogeneous distribution of ${ }^{40} \mathrm{Ar}^{*}$ in the original biotite. After being placed in a hydrothermal bomb (for 9.05 days with $5-20 \%$ water at $700^{\circ} \mathrm{C}$ ), the age spectrum of the biotite displayed a rapid decrease from initially old dates (1275 Ma) down to a plateau (at $234 \mathrm{Ma}$ ) extending over the last $80 \%$ of the total ${ }^{39} \mathrm{Ar}$ released. Harrison et al. (1985) attributed the shape of this age spectrum to an artifact of the vacuum extraction technique, resulting from the dehydroxylation of the biotite. It seems very unlikely, however, that any
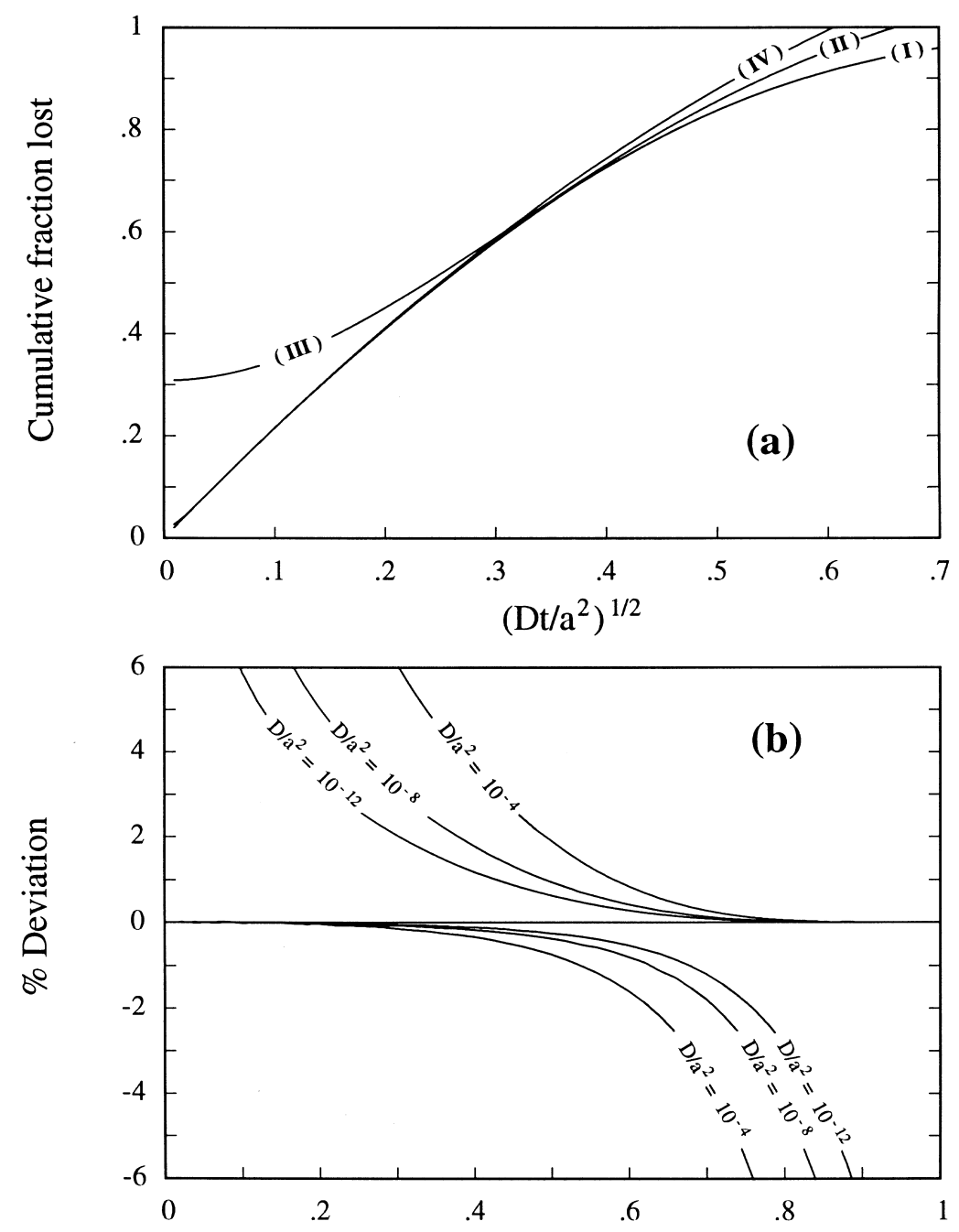

Cumulative fraction lost

Fig. 12. (a) Fractional loss for a cylindrical crystal according to Eq. (1) using the first 20 terms of the exact solution (I), and the approximation equations (II and III) (Eqs. (2) and (3), in text). If only the first two terms of Eq. (2) are used, the fraction lost is shown as (IV). (b) Underestimated and overestimated $D / a^{2}$ (shown as percent of deviation from the true value) caused by using the approximation equations (Eqs. (4) and (5), in text). The percent deviation is a function of the cumulative fraction lost and $D / a^{2}$. The curves in the upper part of the diagram represent $D / a^{2}$ calculated from Eq. (5) in the text, whereas those in the lower part represent $D / a^{2}$ calculated from Eq. (4). In general, a value of $F=0.6$ has been used to mark the transition between the use of either Eq. (4) or Eq. (5). 
dehydroxylation process can cause anomalously old dates in a biotite age spectrum. Instead, these dates could be the result of the rapid release of an excessargon component residing in structural defects in the mineral. When the biotite was heated in the hydrothermal bomb, the ${ }^{40} \mathrm{Ar}^{*}$ lost from the biotite would increase the ${ }^{40} \mathrm{Ar} /{ }^{36} \mathrm{Ar}$ ratio in the surrounding fluid. This "excess" argon component could
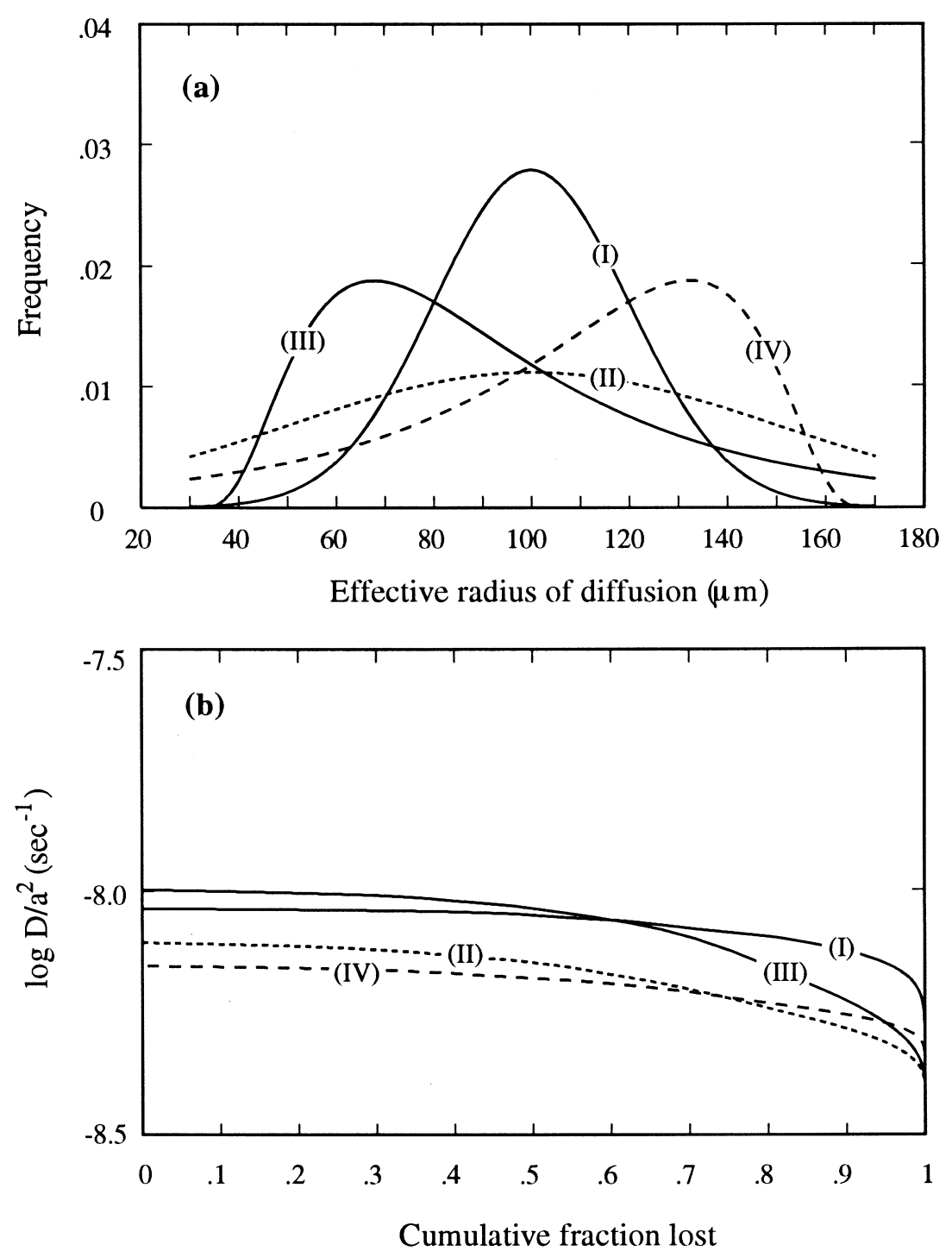

Fig. 13. The distribution of diffusion radii (shown in (a)) used in modelling the effect of a distribution of diffusion radii on the estimation of $D / a^{2}$ (shown in (b)). Curves (I) and (II) represent normal distributions of diffusion radii with a mean value of $100 \mu \mathrm{m}$ but with different standard deviations: $20 \mu \mathrm{m}$ for (I) and $50 \mu \mathrm{m}$ for curve (II). Curves (III) and (IV) represent lognormal and inverse-lognormal distributions, respectively, with a same mean diffusion radius and standard deviation as (II). The curves were constructed by assuming that the argon lost from a bulk sample with the grain size distribution shown in (a) was controlled by volume diffusion with a constant $D$ value $\left(10^{-12} \mathrm{~cm}^{2}\right.$ $\left.\mathrm{s}^{-1}\right)$. 
have been trapped easily in the structural defects and subsequently released via SC diffusion in the lowtemperature steps of the ${ }^{40} \mathrm{Ar} /{ }^{39} \mathrm{Ar}$ step-heating experiment, yielding anomalously old dates.

From the above discussion, the structural defects play an very important role in the Ar released in the low-temperature steps of an ${ }^{40} \mathrm{Ar} /{ }^{39} \mathrm{Ar}$ step-heating experiment. When interpreting the age spectra of natural biotites, two things must be considered. First, any argon (including argon contamination such as excess argon) residing in the structural defects might not be easily detected and SC diffusion is so fast relative to volume diffusion that the $\mathrm{Ar}$ in these defects can be rapidly exchanged. Secondly, most of the temperature steps utilized in typical step-heating experiments are generally higher than the decomposition temperature of biotite (which starts as low as $600^{\circ} \mathrm{C}$ ). At these temperatures, argon release is strongly correlated with the decomposition process. This could homogenize any age gradients, potentially leading to plateau profiles, regardless of the spatial distribution of argon in the crystal. Several examples of biotite plateaus, for samples known either to contain excess argon or to have experienced argon loss (e.g., Berger, 1975; Dallmeyer, 1975; Hanson et al., 1975; Foland, 1983), appear to reflect this phenomenon. Consequently, in ${ }^{40} \mathrm{Ar} /{ }^{39} \mathrm{Ar}$ step-heating experiments, accurate information on the spatial distribution of Ar within biotite will only be obtained from using a temperature schedule that includes more low-temperature steps of longer duration (for $T<$ $600^{\circ} \mathrm{C}$ ) and only if SC diffusion and recoil effects are well-constrained. In certain circumstances, however, such low- $T$ steps may serve as sensitive indicators of the existence of non-radiogenic (e.g., unsupported, excess) ${ }^{40} \mathrm{Ar}$ within biotite, since this type of Ar will preferentially reside in SC pathways. For example, if the ages are obtained in the low- $T$ steps of a step-heating run are lower than those in subsequent high- $T$ steps, then this suggests that excess $\mathrm{Ar}$ may not be an influential component of any dates derived from the experiment. In general, however, it is clear that the most definitive means to evaluate the intragrain spatial distribution of argon in biotite is by using a spot-fusion (laser microprobe) technique.

Many authors have attributed the disturbed age spectra from biotite to be the result of biotite phase changes at high temperature during ${ }^{40} \mathrm{Ar} /{ }^{39} \mathrm{Ar}$ in vacuo heating (Berger, 1975; Hanson et al., 1975; Harrison et al., 1985; Hess et al., 1987). From results of the present study, as well as those from Lo and Onstott (1989), phase changes in biotite during ${ }^{40} \mathrm{Ar} /{ }^{39} \mathrm{Ar}$ step-heating are unlikely to induce any perturbations in the age spectra at high temperatures $\left(T>600^{\circ} \mathrm{C}\right)$; indeed, the decomposition of biotite would probably have the opposite (homogenizing) effect. Consequently, any disturbances reflected in the high-temperature steps of a biotite age spectrum are therefore likely to be caused by effects other than phase changes, e.g., the outgassing of mineral impurities or the artifacts of experimental procedures (e.g., improper blank corrections, uneven heating of the sample, etc.).

The importance of both short-circuit (SC) diffusion and ${ }^{39} \mathrm{Ar}$ recoil in step-heating experiments may have fundamental implications for the volume-diffusion interpretation of spatial distributions of $\mathrm{Ar}$ in other minerals using a ${ }^{40} \mathrm{Ar} /{ }^{39} \mathrm{Ar}$ step-heating technique (e.g., Lovera et al., 1993). From the biotite degassing experiments, the amount of ${ }^{39} \mathrm{Ar}$ that can recoil into extended defects is measurable and nontrivial, confirming the theoretical predictions of Onstott et al. (1995) and Villa (1997). That these defects exist in many minerals and can serve as highdiffusivity pathways throughout individual crystals during the low- $T$ steps of a step-heating run means that an accurate determination of the spatial distribution of ages within mineral grains with the ultimate intent of deriving temperature-time histories from such models is not possible using the data from these steps.

\section{Acknowledgements}

This study was financed by a PRF grant, 19978AC2 (administered by the American Chemical Society) to T.C. Onstott, an NSC grant (NSC80-0202-M002-28) to C.-H. Lo, and an NSERC Individual Research grant to J.K.W. Lee. Special thanks are also due to S. Swapp and N. Brown for guidance with the HTXRD analyses, and to D. Wood for supplying CPC biotite. Constructive comments were provided by Daniele Cherniak and Willis Hames. $[P D]$ 
Appendix A. ${ }^{40} \mathrm{Ar} /{ }^{39} \mathrm{Ar}$ analytical data

\begin{tabular}{|c|c|c|c|c|c|c|c|c|c|c|}
\hline Step no. & $T\left({ }^{\circ} \mathrm{C}\right)$ & $\begin{array}{l}\text { Time } \\
(\mathrm{min})\end{array}$ & $\begin{array}{l}{ }^{36} \mathrm{Ar} \\
\left(\times 10^{-10}\right) \\
\text { CCNTP }\end{array}$ & $\begin{array}{l}{ }^{37} \mathrm{Ar}_{\mathrm{Ca}} \\
\left(\times 10^{-9}\right) \\
\text { CCNTP }\end{array}$ & $\begin{array}{l}{ }^{38} \mathrm{Ar}_{\mathrm{Cl}} \\
\left(\times 10^{-9}\right) \\
\text { CCNTP }\end{array}$ & $\begin{array}{l}{ }^{39} \mathrm{Ar}_{\mathrm{K}} \\
\left(\times 10^{-8}\right) \\
\text { CCNTP }\end{array}$ & $\begin{array}{l}{ }^{40} \mathrm{Ar}^{*} \\
\left(\times 10^{-7}\right) \\
\text { CCNTP }\end{array}$ & $\begin{array}{l}{ }^{39} \mathrm{Ar}_{\mathrm{K}} \\
\mathrm{Cum} . \\
\text { loss }(\%)\end{array}$ & $\begin{array}{l}{ }^{40} \mathrm{Ar}^{*} \\
\mathrm{Cum} . \\
\text { loss }(\%)\end{array}$ & $\begin{array}{l}\text { Apparent } \\
\text { age (Ma) }\end{array}$ \\
\hline \multicolumn{11}{|c|}{ KM-N Biotite (normal step-heating run) } \\
\hline 1 & 550 & 30 & 15.35 & 0.80 & 2.97 & 6.02 & 9.31 & 4.62 & 4.05 & $85.0 \pm 1.8$ \\
\hline 2 & 580 & 60 & 2.81 & 0.26 & 2.86 & 6.27 & 11.11 & 9.43 & 8.89 & $97.2 \pm 1.1$ \\
\hline 3 & 610 & 90 & 2.60 & 0.18 & 3.80 & 8.67 & 15.24 & 16.07 & 15.52 & $96.4 \pm 0.9$ \\
\hline 4 & 640 & 120 & 1.68 & 0.42 & 5.07 & 11.47 & 20.41 & 24.87 & 24.40 & $97.5 \pm 1.0$ \\
\hline 5 & 670 & 150 & 0.94 & 0.26 & 4.86 & 11.09 & 19.88 & 33.38 & 33.05 & $98.3 \pm 1.0$ \\
\hline 6 & 700 & 180 & 0.67 & 0.28 & 4.01 & 9.23 & 16.49 & 40.46 & 40.23 & $97.9 \pm 1.0$ \\
\hline 7 & 750 & 210 & 1.22 & 0.30 & 3.09 & 6.94 & 12.20 & 45.77 & 45.54 & $96.5 \pm 1.4$ \\
\hline 8 & 800 & 240 & 1.54 & 0.52 & 3.04 & 6.87 & 12.08 & 51.04 & 50.80 & $96.5 \pm 1.2$ \\
\hline 9 & 840 & 270 & 1.18 & 0.70 & 2.01 & 4.30 & 7.57 & 54.34 & 54.09 & $96.4 \pm 1.3$ \\
\hline 10 & 880 & 300 & 1.08 & 0.64 & 2.74 & 6.02 & 10.77 & 58.96 & 58.78 & $98.0 \pm 1.3$ \\
\hline 11 & 907 & 330 & 1.42 & 0.21 & 3.62 & 8.16 & 14.50 & 65.21 & 65.09 & $97.4 \pm 1.0$ \\
\hline 12 & 932 & 360 & 2.00 & 0.48 & 0.52 & 11.74 & 20.88 & 74.22 & 74.18 & $97.5 \pm 1.0$ \\
\hline 13 & 957 & 390 & 1.89 & 0.47 & 3.34 & 7.37 & 12.98 & 79.87 & 79.83 & $96.6 \pm 1.1$ \\
\hline 14 & 1000 & 420 & 2.87 & 0.57 & 4.36 & 9.71 & 17.12 & 87.32 & 87.28 & $96.7 \pm 1.2$ \\
\hline 15 & 1040 & 450 & 2.33 & 0.49 & 2.93 & 6.51 & 11.52 & 92.31 & 92.29 & $97.0 \pm 1.0$ \\
\hline 16 & 1090 & 480 & 3.88 & 0.27 & 3.30 & 7.23 & 12.88 & 97.85 & 97.90 & $97.7 \pm 1.0$ \\
\hline 17 & 1150 & 510 & 5.60 & 0.40 & 1.37 & 2.81 & 4.83 & 100.00 & 100.00 & $94.5 \pm 1.1$ \\
\hline \multirow{2}{*}{\multicolumn{6}{|c|}{$\begin{array}{l}\text { Mass }=0.1502 \mathrm{~g} \\
\text { Integrated date }=96.6 \pm 0.9 \mathrm{Ma}\end{array}$}} & \multicolumn{5}{|c|}{$J$-value $=0.003123 \pm 0.000029$} \\
\hline & & & & & & Plateau da & $7.2 \pm 0.9 \mathrm{M}$ & ps 2-17) & & \\
\hline \multicolumn{11}{|c|}{$\mathrm{KM}-400$ Biotite $\left(400^{\circ} \mathrm{C}\right.$ isothermal run $)$} \\
\hline 1 & 400 & 5 & 9.84 & 0.22 & 0.96 & 0.44 & 0.32 & 0.41 & 0.14 & $32.1 \pm 3.8$ \\
\hline 2 & 400 & 15 & 6.11 & 0.08 & 0.66 & 0.47 & 0.53 & 0.85 & 0.36 & $49.8 \pm 1.2$ \\
\hline 3 & 400 & 30 & 5.03 & 0.24 & 0.39 & 0.62 & 0.91 & 1.42 & 0.74 & $64.5 \pm 3.4$ \\
\hline 4 & 400 & 50 & 3.64 & 0.26 & 0.30 & 0.62 & 1.18 & 1.99 & 1.24 & $83.6 \pm 2.8$ \\
\hline 5 & 400 & 80 & 3.61 & 0.35 & 0.31 & 0.65 & 1.27 & 2.59 & 1.78 & $85.8 \pm 1.5$ \\
\hline 6 & 400 & 130 & 3.80 & 0.14 & 0.30 & 0.70 & 1.36 & 3.25 & 2.36 & $84.7 \pm 2.7$ \\
\hline 7 & 400 & 220 & 3.68 & 0.14 & 0.33 & 0.78 & 1.62 & 3.97 & 3.04 & $90.5 \pm 2.1$ \\
\hline 8 & 400 & 370 & 3.36 & 0.07 & 0.34 & 0.89 & 1.86 & 4.80 & 3.83 & $91.3 \pm 3.1$ \\
\hline 9 & 400 & 610 & 2.78 & 0.06 & 0.34 & 0.91 & 1.90 & 5.64 & 4.64 & $91.7 \pm 2.9$ \\
\hline 10 & 400 & 850 & 1.59 & 0.18 & 0.23 & 0.63 & 1.33 & 6.23 & 5.20 & $91.9 \pm 3.5$ \\
\hline 11 & 400 & 1150 & 0.98 & 0.15 & 0.18 & 0.61 & 1.36 & 6.79 & 5.78 & $98.1 \pm 1.5$ \\
\hline 12 & 400 & 1580 & 1.02 & 0.17 & 0.20 & 0.67 & 1.51 & 7.42 & 6.42 & $97.7 \pm 1.7$ \\
\hline 13 & 400 & 2170 & 0.82 & 0.07 & 0.24 & 0.69 & 1.55 & 8.06 & 7.08 & $98.4 \pm 2.3$ \\
\hline 14 & 400 & 2800 & 0.64 & 0.04 & 0.22 & 0.60 & 1.35 & 8.62 & 7.65 & $97.8 \pm 2.2$ \\
\hline 15 & 550 & 2830 & 1.04 & 0.06 & 1.02 & 2.70 & 6.01 & 11.12 & 10.20 & $97.2 \pm 1.1$ \\
\hline 16 & 581 & 2860 & 0.69 & 0.45 & 1.58 & 4.22 & 9.55 & 15.04 & 14.25 & $98.7 \pm 0.8$ \\
\hline 17 & 610 & 2890 & 0.86 & 0.15 & 2.38 & 6.07 & 13.45 & 20.68 & 19.95 & $96.7 \pm 0.7$ \\
\hline 18 & 641 & 2920 & 0.88 & 0.06 & 2.65 & 7.06 & 15.48 & 27.24 & 26.52 & $95.8 \pm 0.7$ \\
\hline
\end{tabular}




\begin{tabular}{|c|c|c|c|c|c|c|c|c|c|c|}
\hline \multicolumn{11}{|c|}{$\mathrm{KM}-400$ Biotite $\left(400^{\circ} \mathrm{C}\right.$ isothermal run $)$} \\
\hline 19 & 670 & 2950 & 0.74 & 0.07 & 3.55 & 9.36 & 20.50 & 35.93 & 35.22 & $95.6 \pm 0.7$ \\
\hline 20 & 700 & 2980 & 0.44 & 0.19 & 2.44 & 6.57 & 14.34 & 42.03 & 41.30 & $95.3 \pm 1.1$ \\
\hline 21 & 750 & 3010 & 0.58 & 0.08 & 3.16 & 8.45 & 18.53 & 49.88 & 49.16 & $95.7 \pm 0.7$ \\
\hline 22 & 800 & 3040 & 0.78 & 0.07 & 3.30 & 8.35 & 18.34 & 57.63 & 56.94 & $95.9 \pm 0.7$ \\
\hline 23 & 840 & 3070 & 1.52 & 0.77 & 5.02 & 13.09 & 29.33 & 69.79 & 69.38 & $97.8 \pm 0.8$ \\
\hline 24 & 880 & 3100 & 1.39 & 0.83 & 4.49 & 11.79 & 26.04 & 80.74 & 80.43 & $96.5 \pm 0.7$ \\
\hline 25 & 907 & 3030 & 1.45 & 0.42 & 4.78 & 12.55 & 27.66 & 92.40 & 92.16 & $96.2 \pm 0.7$ \\
\hline 26 & 932 & 3160 & 0.33 & 0.06 & 1.67 & 4.41 & 9.75 & 96.49 & 96.29 & $96.6 \pm 0.9$ \\
\hline 27 & 957 & 3190 & 0.04 & 0.07 & 0.75 & 1.92 & 4.37 & 98.27 & 98.15 & $99.2 \pm 0.8$ \\
\hline 28 & 1000 & 3220 & 0.59 & 0.46 & 0.36 & 1.08 & 2.42 & 99.27 & 99.18 & $97.9 \pm 2.2$ \\
\hline 29 & 1041 & 3250 & 1.12 & 0.50 & 0.23 & 0.63 & 1.40 & 99.86 & 99.77 & $97.5 \pm 4.4$ \\
\hline 30 & 1090 & 3280 & 1.34 & 1.10 & 0.00 & 0.08 & 0.29 & 99.93 & 99.90 & $158.4 \pm 41.5$ \\
\hline 31 & 1150 & 3310 & 1.42 & 0.06 & 0.00 & 0.07 & 0.25 & 100.00 & 100.00 & $145.0 \pm 58.8$ \\
\hline Ma & $\mathrm{g}$ & & & & & $J$-value & $486 \pm 0$ & & & \\
\hline Inte & $=95$. & Ma & & & & Plateau & $6.2 \pm 0$ & ps 4-29) & & \\
\hline & $e\left(500^{\circ}\right.$ & ermal & & & & & & & & \\
\hline 1 & 500 & 7 & 7.28 & 0.18 & 0.60 & 1.14 & 1.63 & 1.12 & 0.72 & $63.1 \pm 1.6$ \\
\hline 2 & 500 & 27 & 9.78 & 0.29 & 0.98 & 2.07 & 4.13 & 3.14 & 2.54 & $87.3 \pm 1.4$ \\
\hline 3 & 500 & 61 & 4.12 & 0.30 & 0.74 & 1.70 & 3.69 & 4.81 & 4.17 & $94.7 \pm 1.5$ \\
\hline 4 & 500 & 105 & 1.00 & 0.07 & 0.22 & 0.68 & 1.49 & 5.47 & 4.83 & $96.2 \pm 2.1$ \\
\hline 5 & 500 & 206 & 1.81 & 0.06 & 0.68 & 1.67 & 3.70 & 7.10 & 6.46 & $96.9 \pm 1.6$ \\
\hline 6 & 500 & 344 & 1.33 & 0.01 & 0.52 & 1.46 & 3.18 & 8.53 & 7.87 & $95.4 \pm 1.4$ \\
\hline 7 & 500 & 564 & 0.52 & 0.06 & 0.35 & 1.05 & 2.36 & 9.56 & 8.91 & $97.8 \pm 2.1$ \\
\hline 8 & 500 & 879 & 0.73 & 0.05 & 0.59 & 1.58 & 3.47 & 11.10 & 10.44 & $96.1 \pm 1.0$ \\
\hline 9 & 500 & 1258 & 0.58 & 0.03 & 0.48 & 1.35 & 2.90 & 12.42 & 11.72 & $93.8 \pm 2.4$ \\
\hline 10 & 500 & 1750 & 0.08 & 0.03 & 0.51 & 1.53 & 3.46 & 13.92 & 13.25 & $98.9 \pm 1.6$ \\
\hline 11 & 500 & 2222 & 0.07 & 0.05 & 0.37 & 1.06 & 2.31 & 14.95 & 14.27 & $95.5 \pm 2.3$ \\
\hline 12 & 500 & 2670 & 0.04 & 0.44 & 0.31 & 0.96 & 2.08 & 15.89 & 15.19 & $94.3 \pm 3.0$ \\
\hline 13 & 549 & 2700 & 0.06 & 0.05 & 0.34 & 0.94 & 1.96 & 16.81 & 16.05 & $91.1 \pm 2.2$ \\
\hline 14 & 580 & 2730 & 0.08 & 0.06 & 0.85 & 2.28 & 5.02 & 19.04 & 18.27 & $96.2 \pm 1.1$ \\
\hline 15 & 610 & 2760 & 0.45 & 0.01 & 1.83 & 4.74 & 10.37 & 23.68 & 22.85 & $95.6 \pm 0.8$ \\
\hline 16 & 641 & 2790 & 0.49 & 0.08 & 2.73 & 7.00 & 15.36 & 30.53 & 29.63 & $95.8 \pm 0.8$ \\
\hline 17 & 670 & 2820 & 0.61 & 0.05 & 3.35 & 8.58 & 18.83 & 38.93 & 37.94 & $95.8 \pm 0.7$ \\
\hline 18 & 700 & 2850 & 0.12 & 0.46 & 2.41 & 6.27 & 13.72 & 45.06 & 44.00 & $95.6 \pm 0.8$ \\
\hline 19 & 752 & 2880 & 0.87 & 0.45 & 3.26 & 8.15 & 18.26 & 53.03 & 52.06 & $97.8 \pm 1.4$ \\
\hline 20 & 800 & 2910 & 1.00 & 0.60 & 4.19 & 10.40 & 23.47 & 63.20 & 62.42 & $98.5 \pm 0.8$ \\
\hline 21 & 840 & 2940 & 1.63 & 0.27 & 5.16 & 13.21 & 29.65 & 76.13 & 75.51 & $98.0 \pm 0.8$ \\
\hline 22 & 880 & 2970 & 1.36 & 0.23 & 5.11 & 12.64 & 28.85 & 88.50 & 88.25 & $99.6 \pm 1.1$ \\
\hline 23 & 907 & 3000 & 0.70 & 0.35 & 2.43 & 6.48 & 14.26 & 94.84 & 94.55 & $96.1 \pm 1.0$ \\
\hline 24 & 932 & 3030 & 0.20 & 0.34 & 1.04 & 2.73 & 6.27 & 97.51 & 97.31 & $100.2 \pm 1.3$ \\
\hline
\end{tabular}


Appendix A. (continued)

\begin{tabular}{|c|c|c|c|c|c|c|c|c|c|c|}
\hline Step no. & $T\left({ }^{\circ} \mathrm{C}\right)$ & $\begin{array}{l}\text { Time } \\
(\mathrm{min})\end{array}$ & $\begin{array}{l}{ }^{36} \mathrm{Ar} \\
\left(\times 10^{-10}\right) \\
\mathrm{CCNTP}\end{array}$ & $\begin{array}{l}{ }^{37} \mathrm{Ar}_{\mathrm{Ca}} \\
\left(\times 10^{-9}\right) \\
\mathrm{CCNTP}\end{array}$ & $\begin{array}{l}{ }^{38} \mathrm{Ar}_{\mathrm{Cl}} \\
\left(\times 10^{-9}\right) \\
\mathrm{CCNTP}\end{array}$ & $\begin{array}{l}{ }^{39} \mathrm{Ar}_{\mathrm{K}} \\
\left(\times 10^{-8}\right) \\
\mathrm{CCNTP}\end{array}$ & $\begin{array}{l}{ }^{40} \mathrm{Ar}^{*} \\
\left(\times 10^{-7}\right) \\
\text { CCNTP }\end{array}$ & $\begin{array}{l}{ }^{39} \mathrm{Ar}_{\mathrm{K}} \\
\text { Cum. } \\
\text { loss }(\%)\end{array}$ & $\begin{array}{l}{ }^{40} \mathrm{Ar} * \\
\text { Cum. } \\
\text { loss }(\%)\end{array}$ & $\begin{array}{l}\text { Apparent } \\
\text { age (Ma) }\end{array}$ \\
\hline \multicolumn{11}{|c|}{$\mathrm{KM}-500$ Biotite $\left(500^{\circ} \mathrm{C}\right.$ isothermal run $)$} \\
\hline 25 & 957 & 3060 & 0.10 & 0.37 & 0.45 & 1.16 & 2.67 & 98.65 & 98.49 & $100.0 \pm 3.1$ \\
\hline 26 & 1000 & 3090 & 0.10 & 0.84 & 0.20 & 0.67 & 1.56 & 99.30 & 99.18 & $101.6 \pm 4.7$ \\
\hline 27 & 1039 & 3120 & 0.26 & 0.09 & 0.13 & 0.45 & 1.18 & 99.74 & 99.70 & $113.7 \pm 4.9$ \\
\hline 28 & 1100 & 3150 & 1.88 & 0.60 & 0.02 & 0.07 & 0.22 & 99.81 & 99.80 & $132.4 \pm 21.6$ \\
\hline 29 & 1190 & 3180 & 3.26 & 0.20 & 0.08 & 0.19 & 0.46 & 100.00 & 100.00 & $105.0 \pm 10.9$ \\
\hline \multicolumn{6}{|c|}{ Mass $=0.1613 \mathrm{~g}$} & \multicolumn{5}{|c|}{$J$-value $=0.002486 \pm 0.000017$} \\
\hline \multicolumn{6}{|c|}{ Integrated date $=96.8 \pm 0.7 \mathrm{Ma}$} & \multicolumn{5}{|c|}{ Plateau date $=97.1 \pm 0.7 \mathrm{Ma}$ (steps 3-26) } \\
\hline \multicolumn{11}{|c|}{$\mathrm{KM}-600$ Biotite $\left(600^{\circ} \mathrm{C}\right.$ isothermal run $)$} \\
\hline 1 & 600 & 5 & 42.29 & 3.45 & 5.28 & 8.29 & 16.06 & 7.55 & 6.72 & $84.9 \pm 0.7$ \\
\hline 2 & 600 & 12 & 4.13 & 1.56 & 0.95 & 1.96 & 3.98 & 9.33 & 8.39 & $89.1 \pm 1.9$ \\
\hline 3 & 600 & 30 & 8.90 & 1.46 & 3.25 & 7.71 & 16.40 & 16.36 & 15.26 & $92.9 \pm 0.8$ \\
\hline 4 & 600 & 50 & 1.86 & 0.43 & 1.64 & 4.23 & 9.15 & 20.21 & 19.09 & $94.5 \pm 1.3$ \\
\hline 5 & 600 & 80 & 0.83 & 0.00 & 1.74 & 4.40 & 9.74 & 24.22 & 23.17 & $96.6 \pm 1.1$ \\
\hline 6 & 600 & 120 & 0.95 & 0.25 & 1.64 & 4.24 & 9.26 & 28.08 & 27.05 & $95.4 \pm 0.9$ \\
\hline 7 & 600 & 147 & 0.05 & 0.08 & 0.91 & 2.44 & 5.38 & 30.31 & 29.30 & $96.1 \pm 1.2$ \\
\hline 8 & 600 & 198 & 0.05 & 0.29 & 1.32 & 3.60 & 7.97 & 33.59 & 32.63 & $96.6 \pm 1.1$ \\
\hline 9 & 600 & 257 & 0.05 & 0.08 & 1.23 & 3.37 & 7.41 & 36.66 & 35.74 & $96.0 \pm 0.9$ \\
\hline 10 & 600 & 337 & 0.04 & 0.09 & 1.35 & 3.54 & 7.77 & 39.88 & 38.99 & $96.0 \pm 0.9$ \\
\hline 11 & 600 & 440 & 0.05 & 0.07 & 1.40 & 3.73 & 8.17 & 43.28 & 42.41 & $95.7 \pm 0.9$ \\
\hline 12 & 600 & 537 & 0.04 & 0.07 & 1.11 & 2.84 & 6.27 & 45.86 & 45.04 & $96.5 \pm 1.9$ \\
\hline 13 & 600 & 657 & 0.07 & 0.06 & 1.16 & 3.23 & 7.14 & 48.80 & 48.02 & $96.4 \pm 1.0$ \\
\hline 14 & 600 & 810 & 0.03 & 0.00 & 1.21 & 3.21 & 7.12 & 51.73 & 51.00 & $96.7 \pm 0.9$ \\
\hline 15 & 600 & 960 & 0.02 & 0.02 & 0.91 & 2.58 & 5.69 & 54.08 & 53.38 & $96.2 \pm 1.5$ \\
\hline 16 & 600 & 1165 & 0.03 & 0.00 & 0.99 & 2.79 & 6.15 & 56.62 & 55.96 & $96.3 \pm 1.1$ \\
\hline 17 & 600 & 1486 & 0.01 & 0.02 & 1.31 & 3.55 & 7.79 & 59.85 & 59.22 & $95.7 \pm 0.9$ \\
\hline 18 & 600 & 1966 & 0.29 & 0.09 & 1.53 & 4.30 & 9.49 & 63.77 & 63.19 & $96.4 \pm 1.3$ \\
\hline 19 & 600 & 2366 & 0.07 & 0.10 & 0.83 & 2.41 & 5.24 & 65.96 & 65.39 & $95.0 \pm 1.8$ \\
\hline 20 & 600 & 2796 & 0.03 & 0.08 & 0.67 & 2.01 & 4.39 & 67.79 & 67.22 & $95.5 \pm 1.2$ \\
\hline 21 & 611 & 2826 & 0.02 & 0.08 & 0.00 & 0.14 & 0.27 & 67.92 & 67.34 & $83.6 \pm 5.1$ \\
\hline 22 & 641 & 2856 & 0.03 & 0.08 & 0.09 & 0.46 & 0.94 & 68.34 & 67.73 & $89.5 \pm 5.6$ \\
\hline 23 & 670 & 2886 & 0.05 & 0.05 & 0.36 & 1.17 & 2.53 & 69.40 & 68.79 & $94.2 \pm 2.7$ \\
\hline 24 & 700 & 2916 & 0.05 & 0.03 & 0.69 & 2.00 & 4.47 & 71.23 & 70.66 & $97.5 \pm 2.1$ \\
\hline 25 & 750 & 2946 & 0.41 & 0.07 & 1.61 & 4.24 & 9.32 & 75.09 & 74.56 & $96.0 \pm 1.0$ \\
\hline 26 & 800 & 2976 & 1.05 & 0.16 & 2.07 & 5.36 & 11.86 & 79.96 & 79.53 & $96.7 \pm 0.9$ \\
\hline 27 & 840 & 3006 & 1.08 & 0.08 & 2.44 & 6.55 & 14.38 & 85.93 & 85.55 & $95.8 \pm 0.7$ \\
\hline 28 & 880 & 3036 & 1.39 & 0.09 & 2.44 & 6.52 & 14.07 & 91.87 & 91.44 & $94.3 \pm 1.1$ \\
\hline 29 & 907 & 3066 & 0.01 & 0.07 & 1.07 & 3.16 & 7.10 & 94.75 & 94.41 & $98.0 \pm 1.0$ \\
\hline 30 & 932 & 3096 & 0.45 & 0.06 & 0.71 & 2.03 & 4.61 & 96.60 & 96.34 & $99.1 \pm 2.1$ \\
\hline
\end{tabular}


KM-600 Biotite $\left(600^{\circ} \mathrm{C}\right.$ isothermal run)

$\begin{array}{lccc}\text { KM-600 Biotite }\left(600^{\circ} \mathrm{C} \text { isothermal run }\right) \\ 31 & 957 & 3126 & 0.67 \\ 32 & 1000 & 3156 & 1.03 \\ 33 & 1040 & 3186 & 1.16 \\ 34 & 1090 & 3216 & 1.65 \\ 35 & 1160 & 3246 & 3.49\end{array}$

$\begin{array}{ll}0.10 & 0.40 \\ 0.41 & 0.52 \\ 0.06 & 0.19 \\ 0.07 & 0.00 \\ 0.09 & 0.00\end{array}$

1.34
1.66
0.62
0.04
0.07

2.98
3.71
1.49
0.32
0.24

97.83
99.33
99.90

97.59

$96.7 \pm 2.4$

$J$-value

0.24

99.93

99.14

99.77

$97.8+2.3$

Mass $=0.1156 \mathrm{~g}$

Integrated date $=95.1 \pm 0.7 \mathrm{Ma}$

Plateau date $=95.8 \pm 0.7 \mathrm{Ma}$ (steps 2-33)

KM-800 Biotite $\left(800^{\circ} \mathrm{C}\right.$ isothermal run)

\begin{tabular}{|c|c|c|c|c|c|c|c|c|c|c|}
\hline 1 & 650 & 30 & 51.48 & 0.46 & 14.19 & 33.83 & 73.16 & 29.93 & 29.22 & $94.5 \pm 0.8$ \\
\hline 2 & 750 & 60 & 5.76 & 0.56 & 11.46 & 30.37 & 67.91 & 56.80 & 56.34 & $97.6 \pm 1.2$ \\
\hline 3 & 800 & 65 & 2.92 & 0.96 & 2.92 & 7.46 & 16.26 & 63.40 & 62.83 & $95.2 \pm 1.0$ \\
\hline 4 & 800 & 77 & 0.24 & 0.46 & 0.79 & 1.99 & 4.44 & 65.16 & 64.60 & $97.5 \pm 0.7$ \\
\hline 5 & 800 & 90 & 0.60 & 0.49 & 1.64 & 4.38 & 9.84 & 69.03 & 68.53 & $98.0 \pm 0.8$ \\
\hline 6 & 800 & 116 & 0.17 & 0.16 & 0.90 & 2.36 & 5.27 & 71.12 & 70.64 & $97.5 \pm 1.7$ \\
\hline 7 & 800 & 136 & 0.43 & 0.19 & 1.19 & 3.11 & 6.85 & 73.87 & 73.37 & $96.1 \pm 1.0$ \\
\hline 8 & 800 & 167 & 0.06 & 0.06 & 0.80 & 2.21 & 4.89 & 75.83 & 75.32 & $96.5 \pm 1.1$ \\
\hline 9 & 800 & 207 & 0.06 & 0.06 & 0.78 & 2.21 & 4.90 & 77.79 & 77.28 & $96.6 \pm 1.6$ \\
\hline 11 & 800 & 317 & 0.08 & 0.07 & 0.69 & 1.95 & 4.32 & 81.49 & 80.98 & $96.9 \pm 1.1$ \\
\hline 12 & 800 & 397 & 0.08 & 0.06 & 0.63 & 1.80 & 4.00 & 83.08 & 82.58 & $96.8 \pm 1.3$ \\
\hline 13 & 800 & 497 & 0.53 & 0.06 & 0.57 & 1.64 & 3.65 & 84.54 & 84.04 & $97.2 \pm 1.9$ \\
\hline 14 & 800 & 597 & 0.13 & 0.05 & 0.40 & 1.26 & 2.81 & 85.65 & 85.16 & $97.5 \pm 1.6$ \\
\hline 15 & 800 & 717 & 0.07 & 0.05 & 0.42 & 1.17 & 2.69 & 86.69 & 86.24 & $100.3 \pm 2.0$ \\
\hline 16 & 800 & 870 & 0.07 & 0.07 & 0.33 & 1.11 & 2.57 & 87.67 & 87.26 & $100.8 \pm 1.4$ \\
\hline 17 & 800 & 1020 & 0.06 & 0.05 & 0.25 & 0.81 & 1.86 & 88.38 & 88.01 & $100.9 \pm 1.9$ \\
\hline 18 & 800 & 1240 & 0.44 & 0.04 & 0.27 & 0.91 & 2.11 & 89.19 & 88.85 & $100.8 \pm 1.9$ \\
\hline 20 & 841 & 1610 & 0.04 & 0.04 & 0.00 & 0.10 & 0.23 & 90.12 & 89.81 & $96.9 \pm 4.3$ \\
\hline 21 & 881 & 1640 & 0.06 & 0.02 & 0.35 & 1.14 & 2.53 & 91.13 & 90.82 & $96.8 \pm 3.1$ \\
\hline 22 & 908 & 1670 & 0.07 & 0.02 & 0.56 & 1.62 & 3.69 & 92.56 & 92.29 & $99.3 \pm 1.7$ \\
\hline 23 & 935 & 1700 & 0.01 & 0.01 & 1.01 & 2.72 & 6.10 & 94.97 & 94.73 & $98.0 \pm 1.5$ \\
\hline 24 & 957 & 1730 & 0.02 & 0.06 & 0.72 & 1.93 & 4.39 & 96.68 & 96.48 & $98.9 \pm 1.5$ \\
\hline 25 & 1002 & 1760 & 0.10 & 0.07 & 0.59 & 1.71 & 3.84 & 98.19 & 98.01 & $98.2 \pm 1.6$ \\
\hline 26 & 1040 & 1790 & 0.83 & 0.56 & 0.69 & 1.88 & 4.29 & 99.85 & 99.73 & $99.6 \pm 1.8$ \\
\hline 27 & 1100 & 1820 & 1.35 & 0.68 & 0.00 & 0.05 & 0.36 & 99.90 & 99.87 & $273.9 \pm 38.5$ \\
\hline 28 & 1190 & 1850 & 2.92 & 0.05 & 0.00 & 0.11 & 0.33 & 100.00 & 100.00 & $123.0 \pm 18.7$ \\
\hline \multicolumn{6}{|c|}{ Mass $=0.1683 \mathrm{~g}$} & \multicolumn{5}{|c|}{$J$-value $=0.002486 \pm 0.000017$} \\
\hline \multicolumn{6}{|c|}{ Integrated date $=96.7 \pm 0.7 \mathrm{Ma}$} & \multicolumn{5}{|c|}{ Plateau date $=96.6 \pm 0.7 \mathrm{Ma}($ steps $1-26)$} \\
\hline
\end{tabular}


Appendix A. (continued)

\begin{tabular}{|c|c|c|c|c|c|c|c|c|c|c|}
\hline Step no. & $T\left({ }^{\circ} \mathrm{C}\right)$ & $\begin{array}{l}\text { Time } \\
(\min )\end{array}$ & $\begin{array}{l}{ }^{36} \mathrm{Ar} \\
\left(\times 10^{-10}\right) \\
\text { CCNTP }\end{array}$ & $\begin{array}{l}{ }^{37} \mathrm{Ar}_{\mathrm{Ca}} \\
\left(\times 10^{-9}\right) \\
\mathrm{CCNTP}\end{array}$ & $\begin{array}{l}{ }^{38} \mathrm{Ar}_{\mathrm{Cl}} \\
\left(\times 10^{-9}\right) \\
\mathrm{CCNTP}\end{array}$ & $\begin{array}{l}{ }^{39} \mathrm{Ar}_{\mathrm{K}} \\
\left(\times 10^{-8}\right) \\
\mathrm{CCNTP}\end{array}$ & $\begin{array}{l}{ }^{40} \mathrm{Ar}^{*} \\
\left(\times 10^{-7}\right) \\
\text { CCNTP }\end{array}$ & $\begin{array}{l}{ }^{39} \mathrm{Ar}_{\mathrm{K}} \\
\text { Cum. } \\
\text { loss }(\%)\end{array}$ & $\begin{array}{l}{ }^{40} \mathrm{Ar}^{*} \\
\text { Cum. } \\
\text { loss }(\%)\end{array}$ & $\begin{array}{l}\text { Apparent } \\
\text { age (Ma) }\end{array}$ \\
\hline \multicolumn{11}{|c|}{$C P C-N$ Biotite (normal step-heating run) } \\
\hline 1 & 550 & 30 & 8.40 & 0.35 & 2.68 & 4.04 & 4.90 & 3.39 & 3.22 & $53.6 \pm 0.7$ \\
\hline 2 & 580 & 60 & 1.83 & 1.79 & 4.04 & 6.47 & 8.26 & 8.83 & 8.66 & $56.4 \pm 0.5$ \\
\hline 3 & 609 & 90 & 2.30 & 2.09 & 7.19 & 11.51 & 14.60 & 18.49 & 18.26 & $56.0 \pm 0.5$ \\
\hline 4 & 640 & 120 & 1.41 & 3.16 & 8.82 & 14.44 & 18.47 & 30.62 & 30.41 & $56.5 \pm 0.4$ \\
\hline 5 & 670 & 150 & 0.77 & 2.54 & 9.29 & 15.21 & 19.46 & 43.40 & 43.21 & $56.5 \pm 0.4$ \\
\hline 6 & 700 & 180 & 0.35 & 1.17 & 7.07 & 11.46 & 14.61 & 53.02 & 52.82 & $56.3 \pm 0.4$ \\
\hline 7 & 750 & 210 & 0.08 & 1.36 & 3.78 & 6.13 & 7.82 & 58.18 & 57.96 & $56.3 \pm 0.4$ \\
\hline 8 & 800 & 240 & 0.19 & 0.66 & 2.01 & 3.22 & 4.15 & 60.88 & 60.69 & $56.8 \pm 0.5$ \\
\hline 9 & 841 & 270 & 0.78 & 0.85 & 2.44 & 3.93 & 5.06 & 64.19 & 64.01 & $56.7 \pm 0.8$ \\
\hline 10 & 880 & 300 & 1.15 & 0.90 & 2.92 & 4.69 & 6.08 & 68.13 & 68.01 & $57.2 \pm 0.9$ \\
\hline 11 & 907 & 330 & 1.88 & 0.39 & 2.90 & 4.69 & 5.94 & 72.06 & 71.92 & $56.0 \pm 0.6$ \\
\hline 12 & 932 & 360 & 0.50 & 0.40 & 2.48 & 3.96 & 5.07 & 75.39 & 75.25 & $56.5 \pm 0.7$ \\
\hline 13 & 958 & 390 & 1.20 & 0.09 & 2.99 & 4.79 & 6.18 & 79.42 & 79.32 & $56.9 \pm 0.7$ \\
\hline 14 & 1000 & 420 & 2.36 & 1.31 & 4.16 & 6.96 & 8.82 & 85.26 & 85.12 & $56.0 \pm 0.4$ \\
\hline 15 & 1040 & 450 & 3.46 & 2.03 & 4.31 & 6.58 & 8.40 & 90.79 & 90.65 & $56.4 \pm 0.5$ \\
\hline 16 & 1091 & 480 & 3.85 & 2.00 & 4.32 & 7.34 & 9.28 & 96.95 & 96.76 & $55.9 \pm 0.5$ \\
\hline 17 & 1150 & 520 & 7.31 & 2.05 & 2.20 & 3.55 & 4.63 & 99.94 & 99.80 & $57.5 \pm 1.0$ \\
\hline 18 & 1190 & 550 & 2.83 & 0.19 & 0.03 & 0.07 & 0.30 & 100.00 & 100.00 & $174.3 \pm 24.1$ \\
\hline \multirow{2}{*}{\multicolumn{6}{|c|}{$\begin{array}{l}\text { Mass }=0.1314 \mathrm{~g} \\
\text { Integrated date }=56.4 \pm 0.4 \mathrm{Ma}\end{array}$}} & \multirow{2}{*}{\multicolumn{5}{|c|}{$\begin{array}{l}J \text {-value }=0.002486 \pm 0.000017 \\
\text { Plateau date }=56.4 \pm 0.4 \mathrm{Ma}(\text { steps } 2-17)\end{array}$}} \\
\hline & & & & & & & & & & \\
\hline \multicolumn{11}{|c|}{ CPC-400 Biotite $\left(400^{\circ} \mathrm{C}\right.$ isothermal run) } \\
\hline 1 & 400 & 5 & 6.72 & 0.20 & 0.47 & 0.33 & 0.32 & 0.25 & 0.19 & $42.6 \pm 3.7$ \\
\hline 2 & 400 & 15 & 2.78 & 0.07 & 0.20 & 0.16 & 0.16 & 0.38 & 0.28 & $42.7 \pm 3.3$ \\
\hline 3 & 400 & 30 & 1.57 & 0.02 & 0.15 & 0.12 & 0.12 & 0.47 & 0.35 & $44.7 \pm 2.7$ \\
\hline 4 & 400 & 50 & 0.49 & 0.03 & 0.06 & 0.06 & 0.06 & 0.52 & 0.39 & $44.2 \pm 3.9$ \\
\hline 5 & 400 & 80 & 0.48 & 0.04 & 0.05 & 0.08 & 0.09 & 0.58 & 0.44 & $48.0 \pm 6.2$ \\
\hline 6 & 400 & 130 & 1.26 & 0.05 & 0.12 & 0.13 & 0.14 & 0.68 & 0.52 & $47.6 \pm 5.5$ \\
\hline 7 & 400 & 220 & 0.92 & 0.04 & 0.11 & 0.17 & 0.18 & 0.80 & 0.62 & $47.0 \pm 3.0$ \\
\hline 8 & 400 & 400 & 0.71 & 0.06 & 0.10 & 0.21 & 0.25 & 0.96 & 0.77 & $54.4 \pm 3.8$ \\
\hline 9 & 400 & 700 & 1.44 & 0.05 & 0.26 & 0.43 & 0.53 & 1.29 & 1.08 & $54.3 \pm 2.2$ \\
\hline 10 & 400 & 1070 & 1.39 & 0.07 & 0.29 & 0.47 & 0.60 & 1.65 & 1.43 & $55.7 \pm 2.6$ \\
\hline 11 & 400 & 1550 & 1.09 & 0.05 & 0.32 & 0.51 & 0.65 & 2.04 & 1.81 & $56.3 \pm 1.2$ \\
\hline 12 & 400 & 2090 & 0.78 & 0.03 & 0.23 & 0.41 & 0.50 & 2.35 & 2.11 & $54.5 \pm 4.8$ \\
\hline 13 & 400 & 2800 & 1.26 & 0.08 & 0.34 & 0.56 & 0.68 & 2.78 & 2.51 & $54.0 \pm 4.1$ \\
\hline 14 & 550 & 2830 & 5.21 & 0.09 & 3.70 & 5.69 & 7.29 & 7.12 & 6.78 & $56.6 \pm 0.4$ \\
\hline 15 & 580 & 2860 & 2.54 & 0.00 & 4.67 & 7.31 & 9.55 & 12.70 & 12.38 & $57.7 \pm 0.4$ \\
\hline 16 & 610 & 2890 & 2.90 & 0.15 & 7.16 & 11.16 & 14.56 & 21.23 & 20.92 & $57.6 \pm 0.4$ \\
\hline 17 & 640 & 2920 & 2.10 & 0.14 & 8.78 & 13.88 & 18.09 & 31.83 & 31.54 & $57.5 \pm 0.4$ \\
\hline 18 & 670 & 2950 & 1.65 & 0.10 & 9.35 & 14.78 & 19.21 & 43.12 & 42.81 & $57.4 \pm 0.4$ \\
\hline 19 & 700 & 2980 & 0.58 & 0.09 & 7.04 & 11.12 & 14.52 & 51.61 & 51.33 & $57.6 \pm 0.4$ \\
\hline
\end{tabular}


CPC-400 Biotite $\left(400^{\circ} \mathrm{C}\right.$ isothermal run)

$\begin{array}{lccc}\text { CPC-400 Biotite }\left(400^{\circ} \text { C isothermal run }\right) & \\ 20 & 750 & 3010 & 0.77 \\ 21 & 800 & 3040 & 0.88 \\ 22 & 840 & 3070 & 0.85 \\ 23 & 880 & 3100 & 1.83 \\ 24 & 907 & 3130 & 1.36 \\ 25 & 932 & 3160 & 1.31 \\ 26 & 957 & 3190 & 1.50 \\ 27 & 1000 & 3220 & 1.98 \\ 28 & 1040 & 3250 & 1.92 \\ 29 & 1090 & 3280 & 3.26 \\ 30 & 1149 & 3310 & 4.25 \\ 31 & 1188 & 3340 & 4.51\end{array}$

$\begin{array}{ll}0.06 & 4.24 \\ 0.15 & 2.64 \\ 0.10 & 2.53 \\ 0.36 & 3.68 \\ 0.04 & 3.17 \\ 0.07 & 3.05 \\ 0.10 & 3.37 \\ 0.10 & 5.42 \\ 0.15 & 4.46 \\ 0.12 & 5.81 \\ 0.12 & 2.28 \\ 0.04 & 0.15\end{array}$

Mass $=0.1808 \mathrm{~g}$

Integrated date $=57.5 \pm 0.4 \mathrm{Ma}$

$\begin{array}{rrrrr}6.68 & 8.72 & 56.71 & 56.45 & 57.6 \pm 0.5 \\ 4.19 & 5.55 & 59.92 & 59.70 & 58.4 \pm 0.5 \\ 3.99 & 5.26 & 62.96 & 62.79 & 58.2 \pm 0.5 \\ 5.70 & 7.53 & 67.32 & 67.20 & 58.3 \pm 0.4 \\ 4.97 & 6.52 & 71.12 & 71.03 & 57.8 \pm 0.4 \\ 4.80 & 6.21 & 74.78 & 74.67 & 57.1 \pm 0.4 \\ 5.33 & 6.90 & 78.86 & 78.71 & 57.1 \pm 0.5 \\ 8.41 & 11.03 & 85.28 & 85.19 & 57.9 \pm 0.4 \\ 6.70 & 8.77 & 90.40 & 90.33 & 57.8 \pm 0.4 \\ 9.01 & 11.77 & 97.28 & 97.24 & 57.7 \pm 0.4 \\ 3.46 & 4.51 & 99.92 & 99.88 & 57.6 \pm 0.5 \\ 0.10 & 0.20 & 100.00 & 100.00 & 82.9 \pm 6.9\end{array}$

CPC-500 Biotite $\left(500^{\circ} \mathrm{C}\right.$ isothermal run)

$\begin{array}{rrrrrl}1 & 500 & 5 & 14.10 & 0.07 & 1.16 \\ 2 & 500 & 15 & 6.59 & 0.38 & 0.75 \\ 3 & 500 & 30 & 2.40 & 0.09 & 0.49 \\ 4 & 500 & 50 & 2.19 & 0.05 & 0.61 \\ 5 & 500 & 80 & 2.03 & 0.05 & 0.73 \\ 6 & 500 & 110 & 1.21 & 0.12 & 0.57 \\ 7 & 500 & 170 & 1.50 & 0.02 & 0.90 \\ 8 & 500 & 250 & 1.25 & 0.03 & 0.87 \\ 9 & 500 & 365 & 1.16 & 0.04 & 0.96 \\ 10 & 500 & 500 & 0.77 & 0.04 & 0.83 \\ 11 & 500 & 740 & 0.99 & 0.05 & 1.17 \\ 12 & 500 & 880 & 0.28 & 0.05 & 0.72 \\ 13 & 500 & 1180 & 0.28 & 0.00 & 0.86 \\ 14 & 500 & 1580 & 0.14 & 0.05 & 0.80 \\ 15 & 500 & 2080 & 0.20 & 0.03 & 1.02 \\ 16 & 500 & 2670 & 0.28 & 0.03 & 1.00 \\ 17 & 550 & 2700 & 0.02 & 0.03 & 0.66 \\ 18 & 580 & 2730 & 0.14 & 0.03 & 1.85 \\ 19 & 610 & 2760 & 0.53 & 0.04 & 4.19 \\ 20 & 640 & 2790 & 0.52 & 0.05 & 7.20 \\ 21 & 668 & 2820 & 0.63 & 0.02 & 8.39 \\ 22 & 700 & 2850 & 0.28 & 0.05 & 7.33 \\ 23 & 752 & 2880 & 0.47 & 0.04 & 3.51 \\ 24 & 800 & 2910 & 0.15 & 0.22 & 1.52 \\ 25 & 840 & 2940 & 0.76 & 0.43 & 1.97 \\ 26 & 880 & 2970 & 0.66 & 0.36 & 2.29 \\ 27 & 907 & 3000 & 0.86 & 0.15 & 2.74 \\ 28 & 933 & 3030 & 0.77 & 0.05 & 2.69 \\ 29 & 957 & 3060 & 0.64 & 0.04 & 2.96 \\ & & & & & \end{array}$

$J$-value $=0.002486+0.000017$

Plateau date $=57.1 \pm 0.4 \mathrm{Ma}($ steps $1-30)$

$\begin{array}{rr}0.71 & 0.71 \\ 0.74 & 0.83 \\ 0.69 & 0.81 \\ 0.92 & 1.09 \\ 1.12 & 1.35 \\ 0.94 & 1.18 \\ 1.46 & 1.86 \\ 1.50 & 1.89 \\ 1.58 & 2.02 \\ 1.40 & 1.76 \\ 1.95 & 2.44 \\ 1.22 & 1.61 \\ 1.46 & 1.89 \\ 1.39 & 1.81 \\ 1.72 & 2.24 \\ 1.84 & 2.36 \\ 1.16 & 1.47 \\ 3.10 & 3.95 \\ 6.86 & 8.76 \\ 11.65 & 14.93 \\ 13.64 & 17.37 \\ 11.99 & 15.32 \\ 5.84 & 7.33 \\ 2.53 & 3.30 \\ 3.27 & 4.13 \\ 3.74 & 4.88 \\ 4.45 & 5.69 \\ 4.46 & 5.63 \\ 4.91 & 6.20\end{array}$

0.56
1.14
1.68
2.40
3.27
4.00
5.14
6.31
7.54
8.64
10.16
11.11
12.25
13.34
14.68
16.12
17.02
19.44
24.80
33.89
44.55
53.91
58.47
60.44
63.00
65.92
69.39
72.87
76.71

0.43
0.94
1.44
2.11
2.94
3.66
4.80
5.96
7.20
8.28
9.78
10.77
11.93
13.04
14.41
15.86
16.77
19.20
24.58
33.76
44.43
53.84
58.34
60.37
62.91
65.91
69.41
72.87
76.67

$43.9 \pm 2.1$

$49.3 \pm 2.0$

$52.1+2.6$

$52.1 \pm 1.5$

$53.3 \pm 2.0$

$55.2 \pm 1.5$

$56.2 \pm 0.8$

$55.7+0.9$

$56.4 \pm 1.2$

$55.4 \pm 1.3$

$55.4+1.0$

$58.3 \pm 1.6$

$57.1+0.8$

$57.3 \pm 0.7$

$57.5 \pm 1.0$

$56.7 \pm 1.3$

$56.2 \pm 1.4$

$56.4 \pm 0.6$

$56.4+0.5$

$56.6 \pm 0.4$

$56.3+0.4$

$56.4 \pm 0.4$

$55.4 \pm 0.5$

$57.7 \pm 0.9$

$55.7 \pm 0.7$

$57.7 \pm 0.6$

$56.5+0.6$

$55.7 \pm 0.4$

$55.8 \pm 0.4$ 
Appendix B. Evaluation of approximation equations in $D / a^{2}$ calculations

As stated by Trull (1989), the calculation of $D / a^{2}$ using the approximation equations [e.g., Eqs. (4) and (5)] may result in significant deviations from the exact $D / a^{2}$ values, because $F$ is a exponential function of $D / a^{2}$ (Eq. (1)). Consequently, a comparison of theoretical $F$ values derived by using a 20-term series of Eq. (1) with those calculated from the approximation equations [Eqs. (2) and (3)] is shown in Fig. 12a. In general, the approximation Eqs. (2) and (3) are consistent with the 20-term series of Eq. (1) over their respective ranges of $F$. However, depending on $F$ and the corresponding $D / a^{2}$ values, Eqs. (4) and (5) could yield significant deviations of the calculated $D / a^{2}$ from the exact value over a range of $F$ values from $0.3-0.75$. As shown in Fig. 12b, Eq. (4) could underestimate $D / a^{2}$ by about $2 \%$ for large $D / a^{2}$ values near an $F$ value of 0.6 , while Eq. (5) will overestimate $D / a^{2}$ in the same region. Thus, any calculation of $D / a^{2}$ according to the approximation equations needs to be corrected for these deviations in the $F$ value range between 0.3 and 0.75 .

Since the fraction lost $(F)$ is a function of the dimensionless parameter $\left(D t / a^{2}\right)$, as shown in the above equations, grains with a small radius of diffusion $(a)$ would be expected to lose much more of their argon than grains with larger $a$ under the same temperature/time conditions, due to the $D / a^{2}$ dependence [Eq. (1)]. This could: (a) potentially cause staircase-shaped age spectra characterized by young dates in the first few steps which then climb to a plateau, as observed in natural feldspar (e.g., Lovera et al., 1989), and (b) also result in the underestima- tion of the activation energy for noble gas diffusion (Fechtig and Kalbitzer, 1966; Trull, 1989).

To examine this effect, the argon diffusion loss from a theoretical bulk sample was modelled with a continuous distribution of diffusion radii, and the calculated fraction lost from the sample was used to derive the corresponding $D / a^{2}$ value according to Eqs. (4) and (5). In this model, the total fraction lost $(F)$ for the whole sample during each time interval is given by:

$F=\sum_{i=1}^{n} Q_{i} G_{i}$

where $Q_{i}$ represents the fraction loss of argon from $i$ th domain in this period of time, as given by Eq. (1); and $G_{i}$ is the fraction of the square of the radius for $i$ th size domain. The fraction of the square of the radius can be used instead of the volume fraction in Eq. (6) because the geometry of diffusion for argon in biotite is assumed to be an infinite cylinder and the volume fraction for such a geometry is independent of the cylinder's height.

By using normal and lognormal distributions of a range of effective diffusion radii (Fig. 13a), the effects on the calculation of $D / a^{2}$ are shown in Fig. 13b. A value of $D=10^{-12} \mathrm{~cm}^{2} / \mathrm{s}$ was assumed, and all of the distributions have a mean $a=100 \mu \mathrm{m}$ with a standard deviations of either $20 \mu \mathrm{m}$ or 50 $\mu \mathrm{m}$. As a result of a range of diffusion radii, $D / a^{2}$ can be underestimated for high $F$ values and overestimated for low $F$ values for a lognormal distribution (Fig. 13b). In contrast, $D / a^{2}$ values will always be underestimated for low $F$ values in normal and inverse-lognormal distributions. More generally, a distribution of effective diffusion radii may result in

\footnotetext{
Notes to Appendix A:The apparent age is obtained according to: $t$ (apparent age $)=(1 / \lambda) \ln \left(\left({ }^{40} \mathrm{Ar}^{*} /{ }^{39} \mathrm{Ar}_{\mathrm{K}}\right)_{\mathrm{s}} J+1\right) . J$-value: Weighted mean of three fusions of irradiation standard P-207 muscovite, utilizing the K-Ar age of 82.6 $\pm 1.0 \mathrm{Ma}$ (Dalrymple et al., 1981); except that for the normal step-heating run for KM-800 biotite, which $J$ was obtained by using standard MMHb-1 hornblende (520.4 $\pm 1.4 \mathrm{Ma}$ ) (Sampson and Alexander, 1987) as a monitor. $J$-value is obtained according to $J=\left(e^{\lambda t m}-1\right) /\left({ }^{40} \mathrm{Ar}^{*} /{ }^{39} \mathrm{Ar}_{\mathrm{K}}\right)_{\mathrm{m}}$; where " $\mathrm{m}$ " is quoted for the standard and "s", the sample.Date $(\mathrm{Ma})=$ the date calculated using the following decay constants: $\lambda=\lambda_{\varepsilon}\left(0.581 \times 10^{-10} \mathrm{yr}^{-1}\right)+\lambda_{\beta}$ $\left(4.961 \times 10^{-10} \mathrm{yr}^{-1}\right) ;{ }^{40} \mathrm{~K} / \mathrm{K}=0.01167$ atom $\%$. The quoted error is one standard deviation and does not include the standard error and the errors in the interference corrections.Integrated date $=$ the date and error calculated from the sum total gas from all steps.Plateau date $=$ the data and error calculated from the sum total gas from those steps, the ages of which fall within 2 S.D. of each other.T $\left({ }^{\circ} \mathrm{C}\right)=$ temperature has an uncertainty of $\pm 2^{\circ} \mathrm{C}$.
} 
either an under- or overestimate of $D / a^{2}$, the deviation increasing with increasing $F$ (Fig. 13b). If $F<0.4$, however, this deviation is typically less than $1.5 \%$ (Fig. 13b).

\section{References}

Aifantis, E.C., 1979. A new interpretation of diffusion in high-diffusivity paths - a continuum approach. Acta Metall. 27, 683-691.

Appleman, D.E., Evans Jr., H.T., 1973. Job 9214: Indexing and Least-squares Refinement of Powder Diffraction Data. U.S. Geological Survey, Computer Contribution 20, U.S. National Technical Information Service, Document PB2-1618.

Bagin, V.I., Gendler, T.S., Dainyak, L.G., Kuz'min, R.N., 1980. Mössbauer, thermomagnetic, and X-ray study of cation ordering and high-temperature decomposition in biotite. Clays and Clay Minerals 28, 188-196.

Bell, I.A., Wilson, C.J.L., 1977. Growth defects in metamorphic biotite. Phys. Chem. Miner. 2, 153-169.

Bell, I.A., Wilson, C.J.L., 1981. Deformation of biotite and muscovite: TEM microstructure and deformation model. Tectonophys. 78, 201-228.

Berger, G.W., 1975. ${ }^{40} \mathrm{Ar} /{ }^{39} \mathrm{Ar}$ step heating of thermally overprinted biotite, hornblende and potassium feldspar from Eldora, Colorado. Earth Planet. Sci. Lett. 26, 387-408.

Bonfiglioli, G., Ferro, A., Mojoni, A., 1961. Electron microscope investigation on the nature of tracks of fission products in mica. J. Appl. Phys. 32, 2499-2503.

Borge, R.J., Dienes, G.J., 1988. An Introduction to Solid State Diffusion. Academic Press, CA, 360 pp.

Brandt, S.B., Voronovskiy, S.N., 1967. Dehydration and diffusion of radiogenic argon in micas. Int. Geol. Rev. 9, 1504-1507.

Brindley, G.W., Lemaitre, J., 1987. Thermal, oxidation and reduction reactions of clay minerals. In: Newman, A.C.D. (Ed.), Chemistry of Clays and Clay Minerals. Mineralogical Society Monograph. no. 6. Longman Scientific and Technical, 480 pp.

Brown, N., Navrotsky, A., 1989. Structural, thermodynamic, and kinetic aspects of disordering in the pseudobrookite-type compound karrooite, $\mathrm{MgTi}_{2} \mathrm{O}_{5}$. Am. Mineral. 74, 902-912.

Catti, M., Ferraris, G., Ivaldi, G., 1989. Thermal strain analysis in the crystal structure of muscovite at $700^{\circ} \mathrm{C}$. Eur. J. Mineral. 1, 625-632.

Crank, J., 1975. The Mathematics of Diffusion. Clarendon Press, Oxford, 414 pp.

Dahl, P.S., 1994. 'Ionic porosity' as a predictor of diffusion parameters in thermochronometric minerals: evidence and tectonic implications. Mineral. Mag. 58A, 205-206.

Dallmeyer, R.D., $1975 .{ }^{40} \mathrm{Ar} /{ }^{39} \mathrm{Ar}$ ages of biotite and hornblende from a progressively remetamorphosed basement terrance: their bearing on interpretation of release spectra. Geochim. Cosmochim. Acta 39, 1655-1669.

Dalrymple, G.B., Alexander, Jr., E.C., Lanphere, M.A., Kraker, G.P., 1981. Irradiation of Samples for ${ }^{40} \mathrm{Ar} /{ }^{39} \mathrm{Ar}$ Dating Using the Geological Survey TRIGA Reactor. U.S. Geol. Surv. Prof. Pap. 1176, p. 55.

Fechtig, H., Kalbitzer, S., 1966. The diffusion of argon in potassium-bearing solids. In: Schaeffer, O.A., Zähringer, J. (Eds.), Potassium-Argon Dating. Springer-Verlag, New York.

Ferrow, E., 1987. Mössbauer and X-ray studies on the oxidation of annite and ferriannite. Phys. Chem. Miner. 14, 270-275.

Foland, K.A., 1983. ${ }^{40} \mathrm{Ar} /{ }^{39} \mathrm{Ar}$ incremental heating plateaus for biotites with excess argon. Chem. Geol. (Isot. Geosci. Sect.) 1, $3-21$.

Gaber, L.J., Foland, K.A., Corbató, C.E., 1988. On the significance of argon release from biotite and amphibole during ${ }^{40} \mathrm{Ar} /{ }^{39} \mathrm{Ar}$ vacuum heating. Geochim. Cosmochim. Acta 52, 2457-2465.

Gerling, E.K., Petrov, B.V., Kol'tsova, T.K., 1966. A comparative study of the activation energy of argon liberation and dehydration energy in amphiboles and biotites. Geochem. Int. 3, 295-305.

Giletti, B.J., 1974. Studies in diffusion I: Ar in phlogopite mica In: Hofmann, A.W., Giletti, B.J., Yorder, H.S., Yund, R.A (Eds.), Geochemical Transport and Kinetics. Carnegie Publ. 634, 107-115.

Grove, M., Harrison, T.M., 1996. ${ }^{40} \mathrm{Ar} *$ diffusion in Fe-rich biotite. Am. Mineral. 81, 940-951.

Hanson, G.N., Gast, P.W., 1967. Kinetic studies in contact metamorphic zones. Geochim. Cosmochim. Acta 31, 1119-1153.

Hanson, G.N., Simmons, K.R., Bence, A.E., 1975. ${ }^{40} \mathrm{Ar} /{ }^{39} \mathrm{Ar}$ spectrum ages for biotite, hornblende and muscovite in a contact metamorphic zone. Geochim. Cosmochim. Acta 39, 1269-1277.

Harrison, L.G., 1961. Influence of dislocations on diffusion kinetics in solids with particular reference to the alkali halides. Trans. Faraday Soc. 57, 1191-1199.

Harrison, T.M., 1981. Diffusion of ${ }^{40} \mathrm{Ar}$ in hornblende. Contrib. Mineral. Petrol. 78, 324-331.

Harrison, T.M., McDougall, I., 1980. Investigations of an intrusive contact, northwest Nelson, New Zealand: II. Diffusion of radiogenic and excess ${ }^{40} \mathrm{Ar}$ in hornblende revealed by ${ }^{40} \mathrm{Ar} /{ }^{39}$ Ar age spectrum analysis. Geochim. Cosmochim. Acta 44, 2005-2020.

Harrison, T.M., Duncan, I., McDougall, I., 1985. Diffusion of ${ }^{40} \mathrm{Ar}$ in biotite: temperature, pressure and compositional effects. Geochim. Cosmochim. Acta 49, 2461-2468.

Hart, E.W., 1957. On the role of dislocations in bulk diffusion. Acta Metall. 5, 597.

Hart, S.R., 1964. The petrology and isotopic-mineral age relations of a contact zone in the Front Range, Colorado. J. Geol. 72, 493-525.

Hazen, R.M., Wones, D.R., 1972. The effect of cation substitutions on the physical properties of trioctahedral micas. Am. Mineral. 57, 103-129.

Hazen, R.M., Wones, D.R., 1978. Predicted and observed compositional limits of trioctahedral micas. Am. Mineral. 63, 885892.

Hess, J.C., Lippolt, H.J., Wirth, R., 1987. Interpretation of ${ }^{40} \mathrm{Ar} /{ }^{39} \mathrm{Ar}$ spectra of biotites: evidence from hydrothermal degassing experiments and TEM studies. Chem. Geol. 66, 137-149. 
Itoh, N., Tanimura, K., 1986. Radiation effects in ionic solids. Radiation Effects 98, 269-287.

Jost, W., 1960. Diffusion in Solids, Liquids, Gases. Academic Press, San Diego, CA.

Kodama, H., Brydon, J.E., 1968. Dehydroxylation of microcrystalline muscovite. Trans. Faraday Soc. 64, 3112-3119.

Le Claire, A.D., Rabinovitch, A., 1984. The mathematical analysis of diffusion in dislocations. In: Murch, G.E., Nowick, A.S. (Eds.), Diffusion in Crystalline Solids. Academic Press, FL, $477 \mathrm{pp}$.

Lee, J.K.W., 1993. The argon release mechnisms of hornblende in vacuo. Chem. Geol. 106, 133-170.

Lee, J.K.W., 1995. Multipath diffusion in geochronology. Contrib. Mineral. Petrol. 120, 60-82.

Lee, J.K.W., Aldama, A.A., 1992. Multipath diffusion: a general numerical model. Comp. Geosci. 18, 531-555.

Lo, C.H., Onstott, T.C., 1989. ${ }^{39}$ Ar recoil artifacts in chloritized biotite. Geochim. Cosmochim. Acta 53, 2697-2711.

Lo, C.H., Onstott, T.C., Lee, C.W., 1993. ${ }^{40} \mathrm{Ar} /{ }^{39} \mathrm{Ar}$ dating of plutonic/metamorphic rocks from Chinmen Island off southeast China and its tectonic implications. J. Geol. Soc. China $36,35-55$

Lovera, O.M., Richter, F.M., Harrison, T.M., 1989. The ${ }^{40} \mathrm{Ar} /{ }^{39} \mathrm{Ar}$ thermochronometry for slowly cooled samples having a distribution of diffusion domain sizes. J. Geophys. Res. 94, 1791717935.

Lovera, O., Heizler, M., Harrison, T., 1993. Argon diffusion domains in K-feldspar: II. kinetic properties of MH-10. Contrib. Mineral. Petrol. 113, 381-393.

MacKenzie, R.C., 1953. The effect of grinding on micas: I. Muscovite. Mineral. Mag. 30, 178-185.

McDougall, I., Harrison, T.M., 1988. Geochronology and Thermochronology by the ${ }^{40} \mathrm{Ar} /{ }^{39} \mathrm{Ar}$ method. Oxford University Press, New York, 212 pp.

Malhotra, V.M., Ogloza, A.A., 1989. FTIR spectra of hydroxyls and dehydroxylation kinetics mechanism in montmorillonite. Phys. Chem. Miner. 16, 386-393.

Meike, A., 1989. In-situ deformation of micas: a high-voltage electron-microscope study. Am. Mineral. 74, 780-796.

Norgett, M.J., Liaiard, A.B., 1968. The migration of inert gases in ionic crystals. Philos. Mag. 18, 1193-1220.

Norwood, C.B., 1974. Radiogenic Argon Diffusion in the Biotite Micas. M.S. Thesis, Brown University, RI, $58 \mathrm{pp}$.

Ohta, T., Takeda, H., Takéuchi, Y., 1982. Mica polytypism: similarities in the crystal structures of coexisting $1 \mathrm{M}$ and $2 \mathrm{M}_{1}$ oxybiotite. Am. Mineral. 67, 298-310.

Onstott, T.C., Peacock, M.W., 1987. Argon retentivity of hornblendes: a field experiment in a slowly-cooled metamorphic terrane. Geochim. Cosmochim. Acta 51, 2891-2903.

Onstott, T.C., Hall, C.M., York, D., 1989. ${ }^{40} \mathrm{Ar} /{ }^{39} \mathrm{Ar}$ thermochronometry of the Imataca Complex, Venezuela. Precambrian Res. 42, 255-291.

Onstott, T.C., Phillips, D., Pringle-Goodell, L., 1991. Laser microprobe measurement of chlorine and argon zonation in hydrous silicates: an ${ }^{40} \mathrm{Ar} /{ }^{39} \mathrm{Ar}$ geospeedometer? Chem. Geol. 90, 145-168.

Onstott, T.C., Miller, M.L., Ewing, R.C., Arnold, G.W., Walsh,
D.S., 1995. Recoil refinements: implications for the ${ }^{40} \mathrm{Ar} /{ }^{39} \mathrm{Ar}$ dating technique. Geochim. Cosmochim. Acta 59, 1821-1834.

Phillips, D., 1991. Argon isotope and halogen chemistry of phlogopite from South African kimberlites: a combined step-heating, laser probe, electron microprobe and TEM study. Chem. Geol. 87, 71-98.

Phillips, D., Onstott, T.C., 1988. Argon isotopic zoning in mantle phlogopite. Geology 16, 542-546.

Pickles, C.S., Kelley, S.P., Reddy, S.M., Wheeler, J., 1997. Determination of high spatial resolution argon isotope variations in metamorphic biotites. Geochim. Cosmochim. Acta 61, 3809-3834.

Price, P.B., Walker, R.M., 1962. Electron microscope observation of a radiation-nucleated phase transformation in mica. J. Appl. Phys. 33, 2625-2628.

Rebbert, C.R., 1986. Biotite Oxidation: an Experimental and Thermodynamic Approach. MSc Thesis, Virginia Polytechnic Institute and State University, $70 \mathrm{pp}$.

Reed, D.J., 1977. A review of recent theoretical developments in the understanding of the migration of helium in metals and its interaction with lattice deffects. Radiation Effects 31, 129-147.

Rouxhet, P.G., Gillard, J.L., Fripiat, J.J., 1972. Thermal decomposition of amosite, crocidolite, and biotite. Mineral. Mag. 38, 583-592.

Sampson, S.D., Alexander, E.C., 1987. Calibration of the interlaboratory ${ }^{40} \mathrm{Ar}-{ }^{39} \mathrm{Ar}$ dating standard, MMHb-1. Chem. Geol. (Isot. Geosci. Sect.) 66, 27-34.

Sanz, J., González-Carreno, T., Gauncedo, R., 1983. On dehydroxylation mechanisms of a biotite in vacuo and in oxygen. Phys. Chem. Miner. 9, 14-18.

Sardarov, S.S., 1961. Bond energy and retention of radiogenic argon in micas. Geochemistry 1, 33-44.

Sletten, V.M., Onstott, T.C., 1998. The effect of the instability of muscovite during in vacuo heating on ${ }^{40} \mathrm{Ar} /{ }^{39} \mathrm{Ar}$ step-heating spectra. Geochim. Cosmochim. Acta 62, 123-142.

Stucki, J.W., Golden, D.C., Roth, C.B., 1984. Effects of reduction and reoxidation of structural iron on the surface charge and dissolution of dioctahedral smectites. Clays and Clay Minerals $32,350-356$.

Tseng, H.-Y., Heaney, P.E., Onstott, T.C., 1995. Characterization of lattice strain induced by neutron irradiation. Phys. Chem. Miner. 22, 399-405.

Tripathi, R.P., Chandra, U., Chandra, R., Lokanathan, S., 1978. A Mössbauer study of the effects of heating biotite, phlogopite and vermiculite. J. Inorg. Nucl. Chem. 40, 1293-1298.

Trull, T.W., 1989. Diffusion of Helium Isotopes in Silicate Glasses and Minerals: Implications for Petrogenesis and Geochronology. Ph.D. dissertation, WHOI/MIT Joint Program in Oceanography, $465 \mathrm{pp}$.

Turner, G., Cadogan, P.H., 1974. Possible effects of ${ }^{39}$ Ar recoil in ${ }^{40} \mathrm{Ar}-{ }^{39} \mathrm{Ar}$ dating. Proc. Lunar Planet. Sci. Conf. 5th, 16011615.

Vedder, W., Wilkins, R.W.T., 1969. Dehydroxylation and rehydroxylation, oxidation and reduction of micas. Am. Mineral. $54,482-509$.

Villa, I., 1997. Direct determination of ${ }^{39} \mathrm{Ar}$ recoil distance. Geochim. Cosmochim. Acta 61, 689-691. 
Westcott, M.R., 1966. Loss of argon from biotite in a thermal metamorphism. Nature 210, 83-84.

Wones, D., 1963. Physical properties of synthetic biotites on the join phlogopite-annite. Am. Mineral. 48, 1300-1321.

Wood, D.J., Stowell, H.H., Onstott, T.C., Hollister, L.S., 1991. ${ }^{40} \mathrm{Ar} /{ }^{39} \mathrm{Ar}$ constraints on the emplacement, uplift and cooling of the Coast Plutonic Complex Sill, SE Alaska. Geol. Soc. Am. Bull. 103 (7), 849-860.

Wright, N., Layer, P.W., York, D., 1991. New insights into thermal history from single grain ${ }^{40} \mathrm{Ar} /{ }^{39} \mathrm{Ar}$ analysis of biotite. Earth Planet. Sci. Lett. 104, 70-79.
Wu, J., Low, P.F., Roth, C.B., 1989. Efects of octahedral-rion reduction and swelling pressure on interlayer distances in Na-nontronite. Clays and Clay Minerals 37, 211-218.

Yund, R.A., Smith, B.M., Tullis, J., 1981. Dislocation-assisted diffusion of oxygen in albite. Phys. Chem. Miner. 7, 185-189.

Yurimoto, H., Morioka, M., Nagasawa, H., 1989. Diffusion in single crystals of melilite: I. Oxygen. Geochim. Cosmochim. Acta 53, 2387-2394. 